\title{
THE MECHANISMS OF TECHNOLOGICAL INNOVATION IN SMEs: A BAYESIAN NETWORK ANALYSIS OF EU REGIONAL POLICY IMPACT ON POLISH FIRMS
}

\author{
Massimo FLORIO ${ }^{1}$, Aleksandra PARTEKA ${ }^{2}$, Emanuela SIRTORI $^{3}$ \\ ${ }^{1}$ University of Milan, Milan, Italy \\ ${ }^{2}$ Gdansk University of Technology, Narutowicza 11/12, 80-233 Gdansk, Poland \\ ${ }^{3}$ Centre for Industrial Studies, Milan, Italy
}

Received 07 July 2017; accepted 28 April 2018

\begin{abstract}
We study the underlying mechanisms of technological innovation in SMEs in the context of ex-post evaluation of European Union's regional policy. Our aim is to explain the observed change in firms' innovativeness after receiving EU support for technological investment. To do so, we take an approach that is novel in innovation studies: a Bayesian Network Analysis to assess the effectiveness of EU policy instrument for technological innovation and to determine the mechanisms by which the policy works within firms. Our data draw from a unique survey of 200 Polish firms that received "Technological Credit" during the 2007-2013 programming period. First, we confirm the short-term positive impact of the EU innovation policy (i.e. a wider range of products/services offered, increased sales and exports). More importantly, we determine the causal chain between economically quantifiable outcomes and behavioural change in the firm, which is an important node in the network of effects generated. We find that only the financially sounder and more internationalised firms managed to take advantage of the policy. These findings suggest that programmes based on technological credits are not well suited to foster innovation in more fragile and domestically oriented SMEs, which may require different policy instruments.
\end{abstract}

Keywords: technological innovation, regional policy, policy impact evaluation, Bayesian Network Analysis, SMEs.

JEL Classification: O31, O33, R11, C11.

\section{Introduction}

This paper studies the mechanisms underlying the observed technological change induced by innovation policy in Small and Medium-sized Enterprises (SMEs) ${ }^{1}$. Our focus is on Technological Credit (TC), a policy instrument supported by the EU.

\footnotetext{
${ }^{1}$ Innovation policy is defined as "public intervention to support the generation and diffusion of new products, processes or services” (Edler, Cunningham, \& Gök, 2016, p. 544).
}

${ }^{\star}$ Corresponding author. E-mail: aparteka@zie.pg.gda.pl

This is an Open Access article distributed under the terms of the Creative Commons Attribution License (http://creativecommons. org/licenses/by/4.0/), which permits unrestricted use, distribution, and reproduction in any medium, provided the original author and source are credited. 
This topic is relevant in the framework of technology-driven growth, a key aspect of development strategies relying on innovation as a major factor of economic growth (Cox \& Rigby, 2013; Dolfsma \& Seo, 2013; Dosi, Freeman, Nelson, Silverberg, \& Soete, 1988; EC, 2010; OECD, 2015; Romer, 1990; Scherer, 1986). The revised OECD innovation strategy (OECD , 2015) recognises the role of innovation in fostering growth through the technology embodied in fixed capital (e.g. ICT), investment in knowledge-based capital, and productivity growth due to innovation and its impact on business dynamism and creative destruction. At the micro level, innovation and knowledge spillovers are considered to be important factors for firms' survival, growth and development (Acs \& Audretsch, 1990; Acs, Audretsch, Braunerhjelm, \& Carlsson, 2009). Of course, innovative activity is not cost-free, and the role of financial constraints has traditionally been at the top of the research agenda on the barriers faced by firms, and in particular SMEs (among others, see Carpenter \& Petersen, 2002; Beck \& Demirguc-Kunt, 2006; Czarnitzki \& Hottenrott, 2011; Czemiel-Grzybowska \& Skowronek-Mielczarek, 2017). The lack of financial resources, in fact, is one of the main factors that impede innovation capacity (Hadjimanolis, 1999; Hueske \& Guenther, 2015; Madrid-Guijarro, Garcia, \& Van Auken, 2009)2 ${ }^{2}$, and a good many policy instruments have been developed, including those of the EU (reviewed in EC, 2015a), to support innovation by SMEs and to help them overcome their financial constraints ${ }^{3}$.

Our study forms part of the growing literature on innovation policy, its mechanisms and effectiveness. Edler and Fagerberg (2017) distinguish three main types of innovation policy: "mission-oriented policies," which provide practical new solutions to broad problems of vital importance to the state (such as defence, military technology and communications, or global warming), creating new technological and industrial landscapes (see Mazzucato \& Semieniuk, 2017); "system-oriented policies," which led to the formation of national innovation systems in the 1990s and have been endorsed by the OECD, among others (see OECD, 2015); and finally, "invention-oriented policies," focusing on R\&D and invention while leaving the exploitation and diffusion of new ideas to the market. This last type of innovation policy is the main point of reference for our own study, in that we concentrate on the mechanisms of policy-supported technological innovation through the removal of financial constraints (Dodgson, Gann, \& Salter, 2008, pp. 54-93) and the market outcomes observed at firms.

Another referent is the literature on strategic management (among others: Burgelman, Maidique, \& Wheelwright, 1996; Dodgson et al., 2008), which offers explanations for technological innovation and examines its mechanisms and the sources of economic success

\footnotetext{
${ }^{2}$ In a meta-analysis of 188 empirical studies, Hueske and Guenther (2015) give a comprehensive account of a series of factors that hamper, delay or block innovation. Their list includes factors observed in: the external environment (external stakeholders: investors, potential employees, suppliers, competitors, customers, the state, society); the organisation (the levers of managerial skill and dynamism: strategy, structure, size, resources, organisational learning, organisational culture); the group (team structure, team climate, team processes, composition of members according to characteristics, leadership style); and the individual (managers' attitudes and abilities, employees' attitudes and abilities).

${ }^{3}$ ERDF measures to support SMEs at EU level include (EC, 2015a): instruments designed to enhance business creation and support R\&D projects, the commercialisation of innovative products, access to and diffusion of ICT services for SMEs, the development of infrastructure targeting the business sector (incubator facilities, logistics centres, congress venues, technology parks, etc.), capacity building, networking and other activities to help SMEs go international, such as participation in fairs.
} 
(or failure), assessed from the perspective of the innovative firm. In a widely cited paper, Teece (1986) focuses on the context to explain why, in the presence of imitators and competitors, innovating firms often fail to get economically significant returns, even when their innovation (say, a new product) brings welfare gains for consumers. Teece (1986) indicates the great importance of proper business strategy (integration and collaboration) as well as public policy measures (legal protection of the innovator's profits, licensing). The market structure is a relevant contextual determinant that can explain the ability of firms to generate, absorb and profit from innovation, but the empirical evidence is mixed (among others, Chen \& Nie, 2014; Nie, 2013; Tang, 2006; Arrow, 1962) . Dodgson et al. (2008, p. 24) note that the challenges of managing technological innovation go far beyond the technological problems as such and embrace issues of organisation, financing, human resources, marketing and collaboration. Many studies have highlighted the close relationship, the complementarity, between organisational and technological innovations (among others: Battisti \& Stoneman, 2010; Camisón \& Villar-López, 2014; Martínez-Ros \& Labeaga, 2009; Piva, Santarelli, \& Vivarelli, 2005).

Notwithstanding the complexity of these interactions, to date the work on the effectiveness of innovation policy has typically applied the gauge of ex-post additionality. That is, the policy is judged successful if it brings about the expected results in terms of input, output or behavioural additionality 5 . "Input additionality" refers to the degree to which firm inputs increase thanks to the policy support - the impact of policy measures on firms' expenditure, in particular private R\&D expenditure, has been analysed extensively (see, among others: Aerts \& Schmidt, 2008; Alecke, Mitze, Reinkowski, \& Untiedt, 2012; Bronzini \& Iachini, 2014; Czarnitzki \& Licht, 2006; Czarnitzki \& Lopes-Bento, 2013; Clausen, 2009, and the surveys in Zúñiga-Vicente, Alonso-Borrego, Forcadell, \& Galán, 2014 and Becker, 2015). "Output additionality", accordingly, focuses on the policy-induced change in firms' output (sales, exports, patents, etc.), but this has been less widely studied (Bérubé \& Mohnen, 2009; Bronzini \& Piselli, 2016). "Behavioural additionality" can be understood as an effect of the policy that results in durable change in firms' behaviour, helping them to improve innovation capabilities and outcomes (Gök \& Edler, 2012). Methodologically, the study of policy measures' effectiveness (adopted, among others, by: Foreman-Peck, 2013; Hottenrott \& LopesBento, 2014, Moral-Arce \& Paniagua, 2016) often involves comparison of a treated sample (the firms receiving policy support) with a control group (firms not subject to the policy intervention).

This paper will not offer yet another counterfactual analysis (which is not without its own problems, see e.g. Dawid, 2000) or re-estimate the additionality of public support (see Edler et al., 2016, pp. 26-28 for a review of the estimates performed to date). Rather, we

\footnotetext{
$\overline{4}$ Arrow (1962) initially proposed that monopolistic industries tend to be less innovative than competitive ones. Tang (2006) showed that the relationship could be positive or negative depending on specific competition perception and specific innovation activity. Chen and Nie (2014) find that innovation decreases with market power when there is product substitutability; Nie (2013) proves that innovation increases concentration under conditions of spatial duopoly, rebutting the general conclusion of Holmes, Levine and Schmitz (2012), namely that market power lowers the incentive to innovate.

${ }^{5}$ For a thorough recent survey of the evidence on the additionality of various innovation policy measures and their impact, see Edler et al. (2016).
} 
concentrate on the under-researched issue of the within-firm mechanisms of policy-induced technological change. In particular, we address the following research question: What are the firm-level mechanisms behind the observed change in the innovativeness of SMEs due to public support for their technological investment? The question is important insofar as such policy instruments form part of innovation and regional policy in many countries, but not much is known about the mechanisms that determine policy success or failure. Our research question is linked to the so-called "black-box" problem of policy intervention (Astbury \& Leeuw, 2010; Brown \& Mason, 2014) and the possible mismatch between the ways in which policymakers and participating firms view the relevant EU policy measures (Massa \& Testa, $2008)^{6}$.

To address this issue, we inquire more deeply into the mechanisms of change provoked by one specific innovation policy instrument co-financed by the EU, namely Technological Credit (TC), to support technological innovation in Polish SMEs (described in Section 2.2). This analysis sheds new light on the way in which technological innovation works from the perspective of a country that suffers from considerable technological backwardness ${ }^{7}$ and has a correspondingly strong need for innovation policy measures. The sample consists of 200 Polish firms, all over the country, that received TC support. And significantly, on the whole the sample is representative of the entire population of firms receiving TC, which is a pre-condition for accurate inference, and accordingly assures the external validity of our results.

In general, firm-level data on firms' performance are extremely scarce for Poland ${ }^{8}$, lending particular value to our ex-post policy assessment based on micro data from direct, tailored surveys. Firm-level studies on the effectiveness of innovation policy (or R\&D support) in Europe have generally been conducted from the standpoint of enterprises in more advanced countries (Britain in Foreman-Peck, 2013, or Mole, Hart, Roper, \& Saal, 2009; Canada in Bérubé \& Mohnen (2009), or Czarnitzki, Hanel, \& Rosa, 2011; Italy in Bronzini \& Iachini, 2014, or Bronzini \& Piselli, 2016; Norway in Clausen, 2009; Germany in Czarnitzki \& Licht, 2006, or Czarnitzki \& Hottenrott, 2011; Belgium in Czarnitzki \& Lopes-Bento, 2013, or Hottenrott \& Lopes-Bento, 2014; Spain in Moral-Arce \& Paniagua, 2016) ${ }^{9}$. Comparable empirical evidence for firms in the new EU member states is lacking, apart from the study on Hungarian companies by Béres and Závecz (2016).

\footnotetext{
${ }^{6}$ In this context, Bach, Matt and Wolff (2014) use the example of the European Framework Programmes for Research and Technological Development to analyse the extent to which participation in public programmes meets the policymakers' goals. Faber, van Dijk and van Rijnsoever (2016) list a set of incentives and barriers that influence the likelihood of participation in European research programmes by Dutch science-based SMEs.

${ }^{7}$ For instance, the share of innovative enterprises in Poland is just half the EU average (Nieć, 2015, p. 12); see also section 2.1 .

8 The papers available compare the general features of various innovation policies for Polish firms or the allocation of EU funds across firms in selected Polish regions (Golejewska \& Gajda, 2015; Duda, 2012; Jasinski, 2014, Lewandowska, Stopa, \& Humenny, 2015). The samples are typically quite small; the recent paper by Lewandowska et al. (2015) on 394 Polish firms and is among the very few based on wider surveys. Czemiel-Grzybowska and Skowronek-Mielczarek (2017) examine financing difficulties in a sample of 1600 Polish SMEs.

${ }^{9}$ Cross-country analysis also tends to focus on the Western European experience: Venturini, Aristei and Sterlacchini (2016) analyse the effectiveness of R\&D subsidies during the crisis using firm-level data from France, Germany, Italy, Spain, and the UK. Radicic, Pugh, Hollanders, Wintjes and Fairburn (2016) study the effectiveness of public innovation support programs in SMEs in seven EU regions in Germany, Spain, France, Italy, the Netherlands, the UK and Portugal.
} 
At the same time, our results can also be read in a much broader context. An original contribution is offered by our two-step methodology for answering the research question. First we draw on theory-based impact evaluation (Mole et al., 2009; Weiss, 1997a, 1997b; Carvalho \& White, 2004; Astbury \& Leeuw, 2010), structuring the logic of policy intervention as intended by policymakers according to the Realist Evaluation paradigm (Pawson \& Tilley, 1997; Tilley, 2000; Astbury, 2013). In the second step we test the theory by an approach that is new to innovation policy evaluation: namely Bayesian Network Analysis (BNA) applied to survey data. BNA (among others: Daly, Shen, \& Aitken, 2011; Dawid, 2000; Nielsen \& Jensen, 2009; Giffoni et al., 2018; Neapolitan, 2004) has served for analysis, diagnosis, simulation and prediction in a broad variety of fields, ranging from banking and finance through medicine, civil engineering, ecology, robotics, geology and geography to genetics, criminology, and more.

To our knowledge, however, BNA has yet to be applied to EU policy evaluation ${ }^{10}$. This paper thus represents the first application of BNA to discover the mechanisms of change and the causal chain leading to the outcomes of the innovation policy instrument. In this manner, then, it complements other counterfactual studies at firm level that assess the effectiveness of EU funding for SMEs during the recent programming period (2007-2013), based on comparison of treated and untreated samples (for instance, using difference-in-difference and propensity score matching techniques: see, among many, Moral-Arce and Paniagua (2016) on SMEs in Spain or Béres and Závecz (2016) on Hungarian firms). Our two-step methodology allows direct comparison of policymakers' theoretical expectations with the ex-ante views of the recipient firms, which should provide insight into the reasons for the success or failure of the policy support.

Our main findings can be summarised as follows. In the case of these Polish firms the European co-funded policy for technological innovation did in fact succeed in producing the desired effects for the beneficiary SMEs. We identify the mechanisms that explain how these effects are produced. The Polish SMEs that received Technological Credit used these resources to improve their production technologies, enabling them to broaden their range of products/services and increase sales and exports. Importantly, BNA serves to reveal path dependency and the causal chain. There turn out to be some prerequisites for the effectiveness of the EU support: only the financially sounder and more internationalized firms managed to take full advantage of the policy. In addition to the confirmation that the programme produced economically quantifiable outcomes at the funded firms, we also find behavioural change to be an important node in the series of effects that innovation policy produced in Polish SMEs.

The rest of the paper is structured as follows. Section 1 sets our analysis in context, describing the main features of Polish SMEs in terms of innovation performance and technological backwardness and presenting the policy instrument that we assess (Technological Credit). Section 2 describes the Bayesian Network methodology used to discover the mechanisms that determine the instrument's effectiveness and summarises the survey-based data on Polish firms. Section 3 presents our results and explores the way in which theory was put into practice, seeking to determine whether the expected chain of causes and effects from TC actually occurred. The last section concludes with some policy recommendations.

\footnotetext{
${ }^{10}$ There are, however, studies that use BNA for the analysis of SME performance (e.g. Lee, Park, \& Yoon, 2016 on $\mathrm{R} \& \mathrm{D}$ cooperation).
} 


\section{The context}

\subsection{Innovation in Polish firms and constraints on technological investment}

To grasp the specificity of technological innovation support in the Polish case we need to put it in a broader context, historically and politically. Poland's transformation from a centrally planned economy to a market system was painful, resulting in massive unemployment, closures of large companies and difficult restructuring, accompanied by constraints on investment and credit (Konings, Rizov, \& Vandenbussche, 2003). According to the survey presented in Baruk (1997), in the 1990s, the initial period of the transformation, innovativeness was less pronounced in the private than in the public sector; the main impediment to innovation (indicated by $52.5 \%$ of the companies surveyed) was the lack of financial resources. National policies for innovation were not particularly successful. In an analysis of Polish innovation performance in 1989-2000, Jasinski (2003) concludes that there is little correlation between innovation policy and innovation activity. Consequently, the radical change brought by EU membership in 2004 and the prospect of access to EU policies for innovation was highly attractive to Polish firms.

According to the data in Kelley et al. (2016), Poland can still be classified as an efficiency-driven economy ${ }^{11}$ and is 25th out of 189 in the World Bank's Doing Business Ranking. Making the transition to an innovation-driven economy that can maintain high wages and high living standards is possible only if enterprises succeed in competing on the basis of new and specialised products and other innovative solutions (Węcławska, Tarnawa, Nieć, \& Zbierowski, 2015, p. 11). SMEs account for about 50\% of Poland's GDP (Kelley et al., 2016; data refer to 2014), so their role in upgrading the economy is not minor. However, the share of innovative enterprises is very low (23\% in 2012 as against an EU average of $49 \%)^{12}$, and it has actually declined in recent years (Nieć, 2015). R\&D spending in Poland is low. Given its low public and private R\&D expenditure $\left(0.23 \%\right.$ and $0.44 \%$ of GDP respectively ${ }^{13}$, Eurostat, 2014) and scant capacity of its companies and institutions to translate investment into innovation, Poland ranks a poor 22nd of the $28 \mathrm{EU}$ member countries on the European Innovation Scoreboard 2016, with no significant improvement since 2008. It is underperforming the EU average in all the dimensions of innovation (EC, 2016). Thus there is no doubt that Polish firms are quite significantly behind the technological frontier; the question is how far this poor record depends on financial constraints.

Poland currently displays relatively difficult credit conditions, with $34 \%$ of the firms that need loans reported to be credit-constrained (EBRD, 2015a, p. 31) ${ }^{14}$. According to a re-

\footnotetext{
${ }^{11}$ In this classification, the phases of economic development are "factor-driven", "efficiency-driven" and "innovationdriven" (Porter, Sachs, \& McArthur, 2001). In Europe, the efficiency-driven economies are Bulgaria, Croatia, Estonia, Hungary, Latvia, Poland, Romania and Macedonia; the others are innovation-driven (Kelley, Singer, \& Herrington, 2016, p. 7).

12 Poland, Latvia, Romania and Bulgaria are among the EU countries with the lowest share of innovative enterprises (under $30 \%$ in 2012). The top performer in this ranking is Germany, with $67 \%$ of its enterprises classed as innovative in 2012 (Nieć, 2015, p. 12).

${ }^{13}$ R\&D spending by the government sector and by business enterprises.

14 The percentage of credit-constrained firms (those that needed a loan, but either decided not to apply for it or had an application rejected) in 2013-14. The data are from the Business Environment and Enterprise Performance Survey (BEEPS) conducted by the EBRD and the World Bank (details at http://ebrd-beeps.com/).
} 
cent BEEPS survey (EBRD, 2015b) ${ }^{15}$, the three most serious obstacles to doing business, according to the Polish firms surveyed, were still tax administration, competition from the informal sector, and lack of access to finance. A survey conducted directly with Polish SMEs (Czemiel-Grzybowska \& Skowronek-Mielczarek, 2017) confirms that insufficient funds and limited access to bank credit are among the most significant impediments. This is another indication that the development and innovative capacity of Polish firms is still hampered by financial restrictions and that there is a great need for effective use of the support available.

\subsection{Technological Credit as a policy instrument for technological innovation in SMEs ${ }^{16}$}

A recent assessment of the European Regional Development Fund's contribution to development and innovation in SMEs (EC, 2015a) reveals that a wealth of policy instruments were mobilised for this purpose between 2007 and 2013 by regional and national authorities ${ }^{17}$. The largest multi-annual Operational Programme co-funded by the EU during this period aimed at innovation, ICT and R\&D was the Polish "Innovative Economy" Programme. With a total budget of nearly $€ 10$ billion, $85 \%$ of it funded by the ERDF, this programme included a mix of policy instruments to stimulate innovativeness, such as capital investments for technological improvement, consulting services, training and technical assistance ${ }^{18}$.

Our analysis focuses on one particular policy instrument, namely Technological Credit (measure 4.3), which was selected by the European Commission for in-depth analysis ${ }^{19}$. The main goal of TC was to support technological change in SMEs (in order to improve competitiveness) through partial substitution for bank credit. TC consisted of a grant to Polish SMEs that were planning to invest in technology and had already been granted a bank loan. The TC grant served to substitute a part of the commercial bank loan.

The initial public allocation of TC funds amounted to $€ 409.85$ million, but reprogramming raised this to $€ 432.6$ million. The instrument was managed by Bank Gospodarstwa Krajowego (BGK), the Polish National Bank of the Economy, which was selected as the executing body by the Polish Ministry of Infrastructure and Development.

TC was launched in 2009 and initially was allocated for the purchase or leasing of fixed assets and intangible assets (patents, licenses). From 2011, it also supported other types of expenditure, such as the construction and development of fixed assets (buildings, machinery, equipment), the acquisition of land (up to $10 \%$ of eligible spending) and the external advisory services needed to use new technology. All Polish SMEs (enterprises employing fewer than 250 people), regardless of location or sector of activity, were eligible. There were no limits (either lower or upper) to the total value of the technological investment. In order to mini-

\footnotetext{
15 Business Environment and Enterprise Performance Survey, BEEPS 5th edition (http://ebrd-beeps.com/countries/ poland/).

16 This section draws upon EC (2015c, pp. 30-55).

17 See some examples in footnote 3 above.

${ }^{18}$ For a thorough examination of the OP strategy, see the case study described in EC (2015b).

19 This instrument was selected after prior examination of 50 Operational Progammes supported by the ERDF in 2007-2013. See EC (2015a) for a detailed description of the 50 programmes and the rationale for the selection of the Polish OP and Technological Credit.
} 
mise improper conduct by firms (rent-seeking or bribery) the TC instrument was designed for very careful selection of applicants and monitoring of grantees ${ }^{20}$.

There were five calls between July 2009 and October 2012; 1,528 applications were received, most of them in the fourth and fifth calls (Figure 1, left-hand panel). Almost half (45\%) were rejected by the BGK (Figure 1, right-hand panel) and in the end agreements were signed for 717 projects to be realised by 586 different Polish SMEs ${ }^{21}$. By economic sector, $83 \%$ of the beneficiaries were in manufacturing (of which more than $60 \%$ were producers of metal, plastic, other non-metallic mineral products and machinery). By location, $17 \%$ were in the Wielkopolskie region (a significant industrial hub in western Poland), 10\% in Śląskie and $10 \%$ in Podkarpackie. Figure 2 shows the relation between regional TC expenditure and regional GDP growth and unemployment: generally, the more developed regions attracted more funds.

The total TC support for investment projects amounted to $€ 822.7$ million, $€ 415.6$ million in public contributions from the OP and $€ 353$ million in EU financing. Aid intensity (i.e. the ratio of the public support to the total investment) ranged from $18 \%$ to $70 \%$, with an average of 54\%. The average public contribution amounted to $€ 584,000$. Table 1 shows financial accounting data for the beneficiary enterprises according to firm size. Medium-sized enterprises accounted for $48 \%$ of support recipients and realised the largest investment projects.
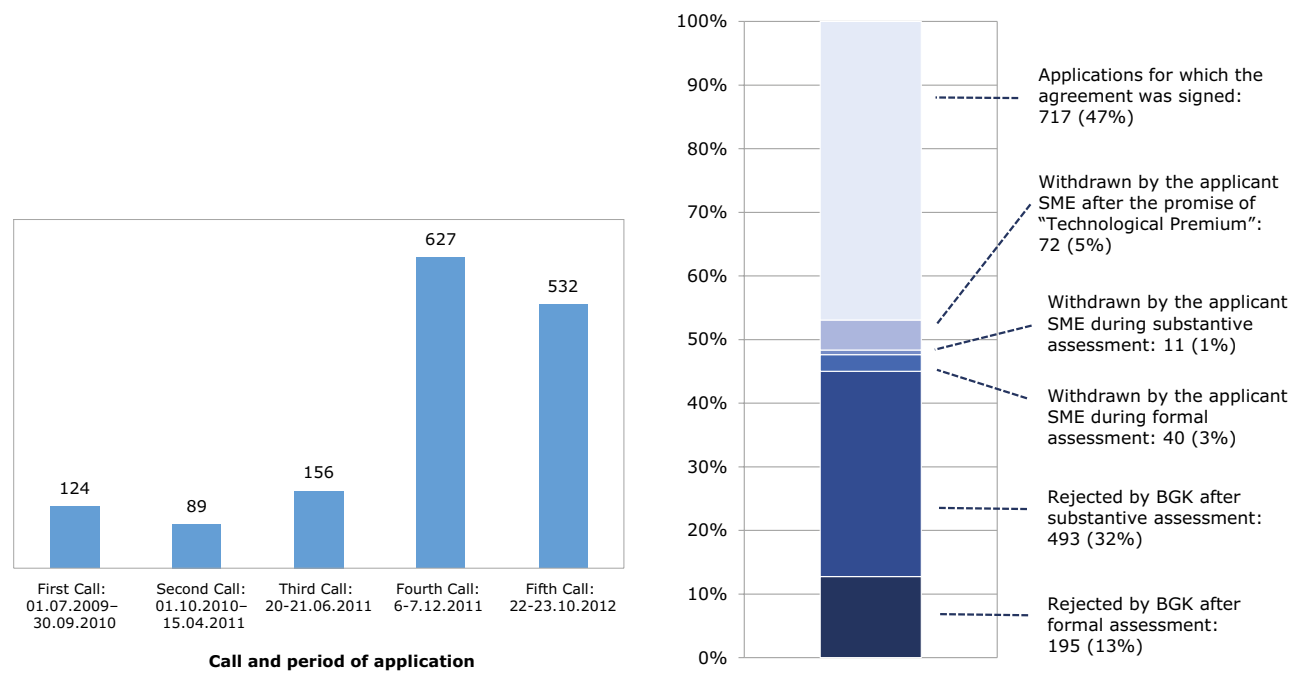

Figure 1. Number of applications and beneficiaries of Technological Credit in Poland (source: CSIL and authors' elaboration of data provided by BGK)

Note: left panel - number of applications for each call; right panel - status of applications received $(\mathrm{n}=1.528)$.

\footnotetext{
${ }^{20}$ The delivery steps are described in detail in the report accompanying this paper (EC, 2015c, Vol. I, p. 31-32).

21 The vast majority ( $86 \%$ ) carried out a single investment project, $14 \%$ more than one ( $12 \%$ - two projects, $2 \%-$ more than two).
} 

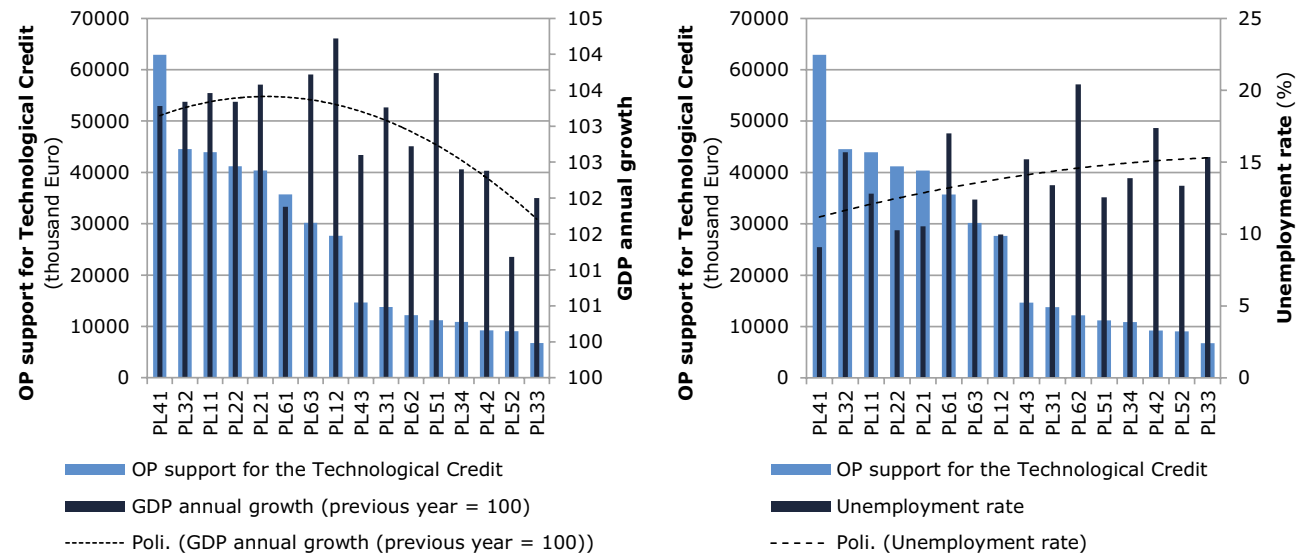

Figure 2. Geographical distribution of OP support for Technological Credit in Poland and regional economic outcomes (source: CSIL and authors' elaboration of MA (Managing Authority) and National Statistical Office data)

Note: left panel - regional GDP growth (average 2008-2012), right panel - unemployment rate (average 2009-2014). Regions: Łódzkie (PL11); Mazowieckie (PL12); Małopolskie (PL21); Śląskie (PL22); Lubelskie (PL31); Podkarpackie (PL32); Świętokrzyskie (PL33); Podlaskie (PL34); Wielkopolskie (PL41); Zachodniopomorskie (PL42); Lubuskie(PL43); Dolnośląskie (PL51); Opolskie (PL52); Kujawsko-pomorskie (PL61); Warmińsko-mazurskie (PL62); Pomorskie (PL63).

Table 1. Financial support to enterprises benefiting from the Technological Credit in Poland, by size class of firm (source: CSIL and authors' elaboration of MA data)

\begin{tabular}{|c|c|c|c|c|c|c|c|c|c|}
\hline & \multicolumn{3}{|c|}{$\begin{array}{l}\text { Micro enterprises } \\
\quad(\mathrm{n}=87)\end{array}$} & \multicolumn{3}{|c|}{$\begin{array}{l}\text { Small enterprises } \\
\qquad(\mathrm{n}=216)\end{array}$} & \multicolumn{3}{|c|}{$\begin{array}{l}\text { Medium enterprises } \\
\qquad(\mathrm{n}=283)\end{array}$} \\
\hline & 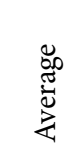 & $\underset{\Xi}{\Xi}$ & 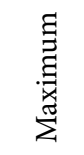 & 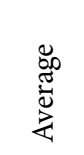 & 声 & 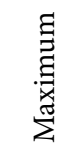 & 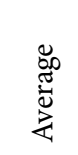 & $\underset{\Xi}{\Xi}$ & 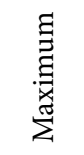 \\
\hline $\begin{array}{l}\text { Value of the investment } \\
\text { project (thousand EUR) }\end{array}$ & 1.061 & 32 & 2.571 & 1.192 & 38 & 4.302 & 1.748 & 25 & 5.165 \\
\hline $\begin{array}{l}\text { Value of public support } \\
\text { from the OP (thousand } \\
\text { EUR) }\end{array}$ & 609 & 19 & 970 & 641 & 23 & 970 & 814 & 12 & 1.001 \\
\hline $\begin{array}{l}\text { Value of EU financing } \\
\text { (thousand EUR) }\end{array}$ & 518 & 16 & 825 & 545 & 19 & 825 & 692 & 11 & 851 \\
\hline $\begin{array}{l}\text { Aid intensity (public } \\
\text { support / value of the } \\
\text { investment) }\end{array}$ & $59 \%$ & $30 \%$ & $70 \%$ & $58 \%$ & $18 \%$ & $70 \%$ & $49 \%$ & $21 \%$ & $61 \%$ \\
\hline
\end{tabular}

Note: Figures are at enterprise level. 


\section{Methodology and data ${ }^{22}$}

\subsection{The evaluation strategy}

Our analysis is performed in two steps: (1) reconstruction of the theory and the logic of intervention underlying the policy instrument; (2) ex-post testing of the theory through a survey of the beneficiary SMEs and use of BNA to determine the reasons for success or failure.

For the first step, among the various theory-based methods we select the Realist Evaluation paradigm (Pawson \& Tilley, 1997) as the one best suited to address the specificities of our analysis, thanks chiefly to the important role that it assigns to context variables (Astbury, 2013) in policies to foster innovation and development in SMEs. This paradigm enables us to address three main questions: (i) What type of intervention works, and for whom? (ii) In what contexts is the policy instrument successful? (iii) What are the mechanisms that determine its effectiveness?

In formal terms, in the first step we construct theoretical Context-Mechanisms-Outcomes (CMO) configurations, which identify and explain the logic of the policy instrument and the underlying theory of change and define the effects expected in a given context. In line with a realistic understanding of mechanisms, these configurations are sensitive to variations in context as well as to the operation of other mechanisms in a particular context (Astbury \& Leeuw, 2010, p. 369). Following Pawson and Tilley (2004), the reconstruction of the theory of the intervention is based on a thorough analysis of the programming documents (described in detail in EC, $2015 \mathrm{a}^{23}$ ) and interviews with the programme architects both at the OP Managing Authority and at BGK.

The theoretical reconstruction led to the development of two separate CMO configurations, i.e. two sets of outcomes with their mechanisms of change and context conditions. The first CMO configuration, illustrated in Figure 3, relates to the expected economic effects of TC. By encouraging SMEs to invest in new technologies (i.e. upgrade their fixed asset base using bank credit), the Technological Credit is expected to help SMEs improve their production processes and thus to market new or upgraded products ${ }^{24}$. At firm level two main results are expected: (i) an improvement in the beneficiary firms' economic performance and (ii) a decrease in their debt burden (which in turn affects economic performance). These firm-level effects are enhanced by expected changes to the context, i.e. the external conditions in which SMEs operate (red boxes in the figure).

Figure 4 refers to the second CMO configuration, corresponding to a different goal of TC as policy instrument: to change the perception of financial instruments and new forms of support initiatives. More specifically, if the SMEs that draw on TC are happy with the formal

\footnotetext{
22 This section draws upon EC (2015c).

23 A backstage documentary analysis involved a detailed analysis of 50 Operational Programmes (OPs) designed in the course of the 2007-2013 programming period, describing the wide range of EU policy instruments to support SMEs (the results of this analysis are set out in the publication accompanying this paper: First Intermediate Report - EC 2015a).

24 This is the logic of the expected mechanism (in blue), which leads to expected outcomes (in green). In the figure all mechanisms, contexts and effects are expressed in the indicative case (e.g. "SMEs find premium attractive" and "SMEs access bank credit to buy modern fixed assets", but in reality every such statement reflects an underlying conditional hypothesis, and so might better be read as "If SMEs find the premium attractive, then it is more likely that they will access the bank credit".
} 
procedure for obtaining the support and with the economic results, then the policy should produce the result of a change in firm's attitudes. The involvement of SMEs with Technological Credit is expected to increase their awareness and effective use of financial instruments and possibly to supplant the TC grant support during the following programming period (2014-2020). In the aggregate, all these expected outcomes imply more efficient use of EU funds.

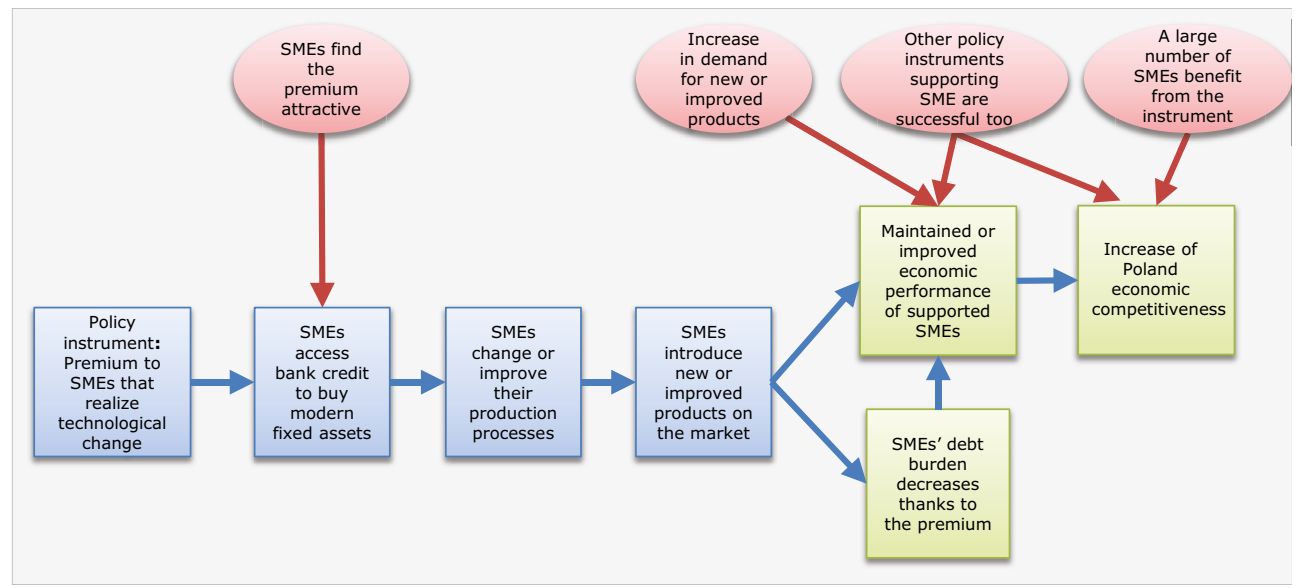

Figure 3. CMO configuration 1 - expected economic effect of the Technological credit instrument directed at Polish SMEs (source: CSIL and authors' elaboration)

Note: outcomes pursued by the policy maker in green boxes; external conditions (context) upon which desired changes occur in red circles; the mechanisms at work along the causal chain leading to the outcomes in blue boxes.

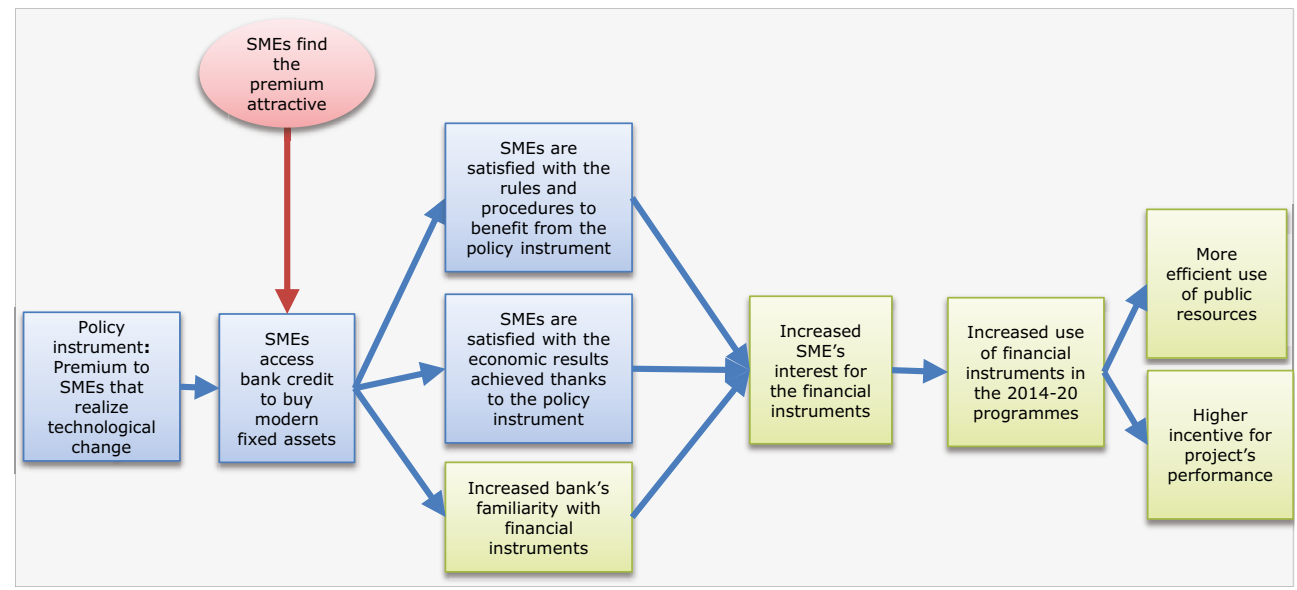

Figure 4. CMO configuration 2 - expected perception of the financial instruments as a result of Technological credit directed at Polish SMEs (source: CSIL and authors' elaboration)

Note: outcomes pursued by the policy maker in green boxes; external conditions (context) upon which desired changes occur in red circles; the mechanisms at work along the causal chain leading to the outcomes in blue boxes. 
Both of these CMO configurations are intended to strictly reflect the theory underlying the policy instruments as designed by the policy makers in the first place and reflected in the programming documents. For this reason, the causal chain leading to desired policy effects within the given context ${ }^{25}$ may appear generic by comparison with the academic literature on innovation policy. The precise objective of our analysis, however, was to determine the extent to which reality matched policy-makers' expectations and the reasons for policy effectiveness.

The second step is empirical testing of the theory behind the policy instrument. We collect information on beneficiary SMEs to verify whether the CMO configurations adequately describe the actual chain of effects triggered by the instrument.

The key questions bearing on success or failure are:

- Has the policy instrument actually helped the SMEs to improve their economic performance, (the first CMO setting)?

- Has it actually increased SMEs' awareness of and ability to use public support (the second CMO setting)?

- Do the changes that stem from the policy support gibe with the logic of intervention, and if not, what are the reasons for deviations from theory in the two settings?

- Has the policy instrument produced any other, possibly unexpected ex-ante, effects in the SMEs; and what is the link between economically quantifiable and other effects?

The first two questions are standard in ex-post policy assessments. The latter two help us to get at what is concealed behind the observed change in the innovativeness of firms owing to public support for technological investment - the main aim of our study.

If they are matched with other favourable context features (successful adoption of other SME support instruments and broad participation of SMEs), all of these mechanisms should lead to a desired outcome at aggregate level: the instrument should contribute to improving the overall competitiveness of Polish industry. The passage from micro to macro level (from successful innovation by single firms to the gain in system-wide competitiveness) can be interpreted in the light of economic theory, which sees technological innovation as a factor in economic growth (Dosi et al., 1988; Romer, 1990). An empirical test of this wider issue goes beyond the scope of our research.

As for the second step, we applied Bayesian Network Analysis (BNA) - described in Section 2.2 - as an ex-post tool for statistical analysis of the survey responses (the data from the Polish firms benefitting from the EU Technological Credit program, described in Section 2.3). This approach allowed us to test whether the expected relations between mechanisms, outcomes and context shown in CMOs actually materialised and, additionally, to detect any other, unexpected mechanisms.

\footnotetext{
$\overline{25}$ In line with Pawson and Tilley's approach the context defines "what conditions are needed for a measure to trigger mechanisms to produce particular outcome patterns" (Tilley, 2000, p. 7). Consequently, in our CMO we consider positive context, whereas the variables of the CMO relate to questionnaire items (provided in the Appendix 1), many of which are on an ordinal scale, reflecting the degree of approval in relation to different possible results (ranging, say, from "not at all" to "very much" or from "strongly disagree" to "strongly agree"). This approach enabled us to rank the observed outcomes of TC from positive to negative, so that negative outputs (realized within the given context and with mechanisms at play) have also been taken into account.
} 


\subsection{Bayesian Network Analysis as a tool for ex-post policy evaluation}

BNA is an advanced but nevertheless intuitive method that combines statistical analysis with graphical representation of the links between variables. We choose BNA for a series of properties that have proven to be useful in the context of ex-post policy assessment to discover the specific mechanisms that lead to the final outcomes observed (see also Giffoni et al., 2018). First, BNA is flexible, which is crucial to testing the theory behind the intervention and detecting hidden or unexpected mechanisms of change (including those not observable in the ex-ante CMO configurations) ${ }^{26}$. Rather than simply measuring the statistical significance of correlations between dependent and independent variables (as in regression analysis), BNA can uncover the system of causal links within the network of variables (which in traditional statistical models could be either dependent or independent). BNA is therefore an innovative tool to inquire into the mechanisms underlying the change provoked by a policy instrument (in our case, a policy for technological innovation).

Formally ${ }^{27}$, Bayesian Networks (BNs), denoted as $B=(G, \Theta)$, are probabilistic graphical models that are defined by two components (Russel \& Norvig, 2003, pp. 496-499; Neapolitan, 2004):

1. a network structure, a directed acyclic graph (DAG), denoted by $G=(\boldsymbol{V}, \mathrm{A})$ in which each node $v_{i} \in \boldsymbol{V}$ corresponds to a random variable $X_{i}$. Specifically, the DAG consists of directed edges $a_{i j} \in A$ connecting the set of random variables (nodes) $X_{1}, X_{2}, \ldots, X_{n}$. An edge from node $X_{i}$ to node $X_{j}$ indicates that a value taken by the variable $X_{j}$ depends on the value taken by the variable $X_{i}$. Node $X_{i}$ is then referred to as "parent" of $X_{j}$, and similarly $X_{j}$ is referred to as "child" of $X_{i}$. The DAG, in other words, represents a hierarchical arrangement of variables - the nodes that are linked (by the arrows) are called "parent" or "child". The DAG thus depicts the network of links between the variables (represented by nodes) and serves as a basis for inference on the causality (direct and indirect) between variables.

2. a set of parameters, denoted by $\Theta$, which provides dependences among the random variables in the form of conditional probability distributions. For discrete random variables, these conditional probabilities are represented by a table (a conditional probability table - CPT) that lists the probability of a child node $X_{j}$ taking each of its values for each value of its parent $X_{i}$, that is $P\left(X_{j}=x_{j} \mid X_{i}=x_{i}\right)=\theta_{x_{j} \mid x_{i}}$. If $X_{j}$ has two or more parents, it depends on their joint distribution, because each pair of parents forms a convergent connection centred on $X_{j}$. In this case, the conditional probability of $X_{j}$ can be calculated using the chain rule (given a topological ordering of $X_{i}$ ) - Russel and Norvig (2003, p. 496):

\footnotetext{
26 Traditionally, the links between the variables of interest are assessed through regression analysis, the dependent variable (outcome) being regressed on its potential determinants as independent or explanatory variables. We use regression analysis as a supporting tool. The results of regression model estimates are reported in an accompanying report - EC (2015c), Vol. II, pp. 39-43.

27 The description here, as well as Appendix 2, is partly based on EC (2015c, Vol. I, pp. 24-29) and on formal explanation of BNA and artificial intelligence methods in: Lauritzen and Spiegelhalter (1988), Spiegelhalter, Dawid, Lauritzen and Cowell (1993), Heckerman, Geiger and Chickering (1995); Dawid (2000); Nadkarni and Shenoy (2001); Neapolitan (2004); Gelman, Carlin, Stern and Rubin (2014), Russell and Norvig (2003).
} 


$$
P\left(X_{j}=x_{j} \mid X_{i+1}=x_{i+1}, \ldots, X_{n}=x_{n}\right)
$$

which can be also expressed as:

$$
P\left(X_{j}=x_{j} \mid X_{i}=x_{i} \text { for each } X_{i} \text { which is parent of } X_{j}\right) .
$$

The foregoing formula, known as Local Markov Property, tells us that each variable in the network is conditionally dependent only on its parents, or similarly, that each variable in the network is conditionally independent of its-non descendants $\left(X_{d e(i)}\right)$, given the set of its parent variables $\left(X_{p a(i)}\right)$. Formally (Russel \& Norvig, 2003, p. 499):

$$
X_{i} \amalg X_{V \backslash d e(i)} \mid X_{p a(i)} \text { for all } i \in V .
$$

Therefore, given a set of random variables $X=\left(X_{i}\right)_{i \in V}$, a BN $B=(G, \Theta)$ defines a unique joint probability distribution (JPD) over $\boldsymbol{V}$, which is broken down into local conditional distributions. The Local Markov Property allows the factorisation of the JPD, that is (Russel \& Norvig, 2003, p. 499):

$$
P_{B}\left(X_{1}=x_{1}, X_{2}=x_{2}, \ldots, X_{n}=x_{n}\right)=\prod_{i=1}^{n} P_{B}\left(X_{i} \mid X_{p a(i)} ; \Theta_{X_{i}}\right)=\prod_{i=j}^{n} \theta_{X_{i} \mid X_{p a(i)}} .
$$

In this framework, the main role of the network structure is to express the JPD as conditional independence relationships among the variables in the model through graphical separation.

In order to facilitate the interpretation of further results, in Figure 5 we show a schematic example of a DAG graph based on survey data and obtained using the GeNIe software. The graph has eight nodes (variables). The tables under each variable show the conditional probabilities generated by the survey data (for instance: $31 \%$ of the interviewees had low value state 0 - of variable 1 ). The arrows between the nodes indicate the dependence between the variables, while the thickness of the arcs shows the degree of influence of one variable upon another (ranging from 0 , weakest, to 1 , strongest).

In the simplest case, the BN is defined by an expert, who specifies the DAG and for each node $X_{i}$ the local distribution for $X_{i}$ conditional upon the related variables. In more complex applications the network structure and parameters must be learned from data, which is pursued within machine learning with the application of one or more types of data-driven learning algorithms. We adopted the Bayesian Search Algorithm and combined analysts' knowledge with statistical data (for details see Appendix 2).

To sum up, using the methodology described above, we construct a BN corresponding to Polish firms' ex-post evaluation of Technological Credit in five steps: (1) design of the questionnaire based on the theory underlying the design of the policy instrument, with questions linked to characteristics of beneficiary enterprises, their performance before and after the policy and other variables relevant to the changes produced by TC (see Appendix 1); (2) collection of microdata from Polish firms that benefited from the policy (described in Section 2.3); (3) processing of the responses for the purpose of BNA ${ }^{28}$; (4) using the survey

\footnotetext{
${ }^{28}$ We use Bayesian Networks in discrete form, in which all the variables are either categorical (yes/no) or ordinal (e.g. "very low" to "very high"). Consequently, we use a hierarchical model to obtain the classes and to transform continuous into discrete variables.
} 


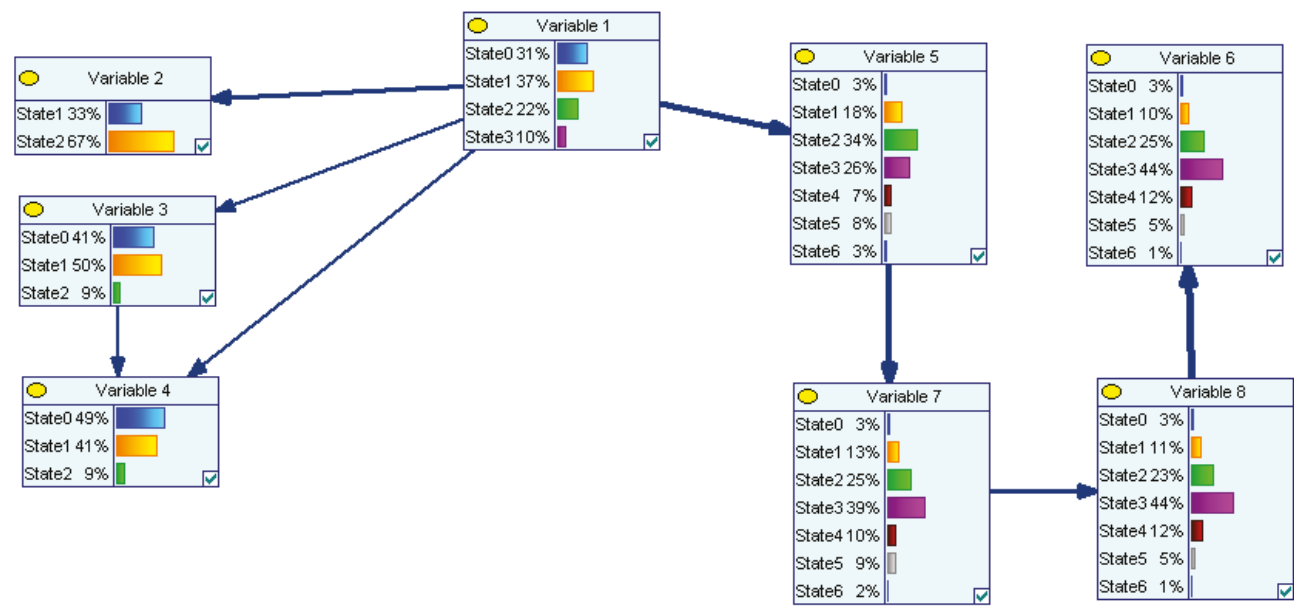

Figure 5. Schematic representation of BN graph (source: CSIL and authors' elaboration)

data, calculation of the local probability distributions between the variables and construction of a DAG showing the network between the various aspects of SMEs' performance and the outcomes of Technological Credit (see Section 3.2); and (5) reassessment of the theory on the basis of the BNA outcomes (see Section 3.3).

\subsection{The survey data}

Our data on the Polish firms examined here were collected by a survey conducted between July and September 2015, intended to cover SMEs supported by the Technological Credit measure. The survey was carried out by the CSIL (Centre for Industrial Studies) in cooperation with the CASE (Centre for Social and Economic Research) and BGK bank (Bank Gospodarstwa Krajowego).

The questionnaire consisted of 28 multiple-choice questions (specifics in Appendix 1). The survey asked: how firms accessed the BGK technological premium; the details of the investment project receiving the TC, for which they had signed a loan contract with the bank; the effects of the investment (changes resulting from the technological innovation), their relative satisfaction with the TC and the access procedure; and any other changes (not necessarily economic) made as a result of their experience with the BGK technological premium.

In the end, the final sample consisted of the 200 enterprises that completed the questionnaire, out of 586 beneficiary firms approached (the resulting response rate of $34.1 \%$ is very good for this type of survey). In order to ensure the representativeness of our sample we compared the characteristics of the sample firms (size, sector of activity, location, value of the investment project, amount of public support) with those of the entire population of beneficiary firms ${ }^{29}$. On this basis the sample proves to approximate the targeted population of firms quite well, which is essential to the validity of the conclusions drawn on the basis of

\footnotetext{
${ }^{29}$ Basic information for all the SMEs that benefitted from TC was obtained (courtesy of BGK).
} 
a BNA run with survey data. In terms of size (Figure 6), the sample's share of medium-sized enterprises was the same as that of the overall population, both $48.5 \%$, that of small enterprises was $37 \%$ (36.9\% in the overall population), and that of micro enterprises was $14.5 \%$ (14.8\%). Most of the firms interviewed were in the regions of Wielkopolskie - PL41 (17\%), Śląskie - PL22 (11\%) and Podkarpackie PL32 (10\%); see Figure 7. By sector (Figure 8), the largest proportion of the firms were engaged in "Manufacture of basic metals and fabricated metal products except machinery and equipment" (22\%), followed by "Manufacture of rubber and plastic products" (16\%). These characteristics, as well as the value of the investment project and the amount of support (Table 2), are quite comparable in the sample and in the overall population, which means that the sample offers the requisite characteristics for rigorous statistical analysis.

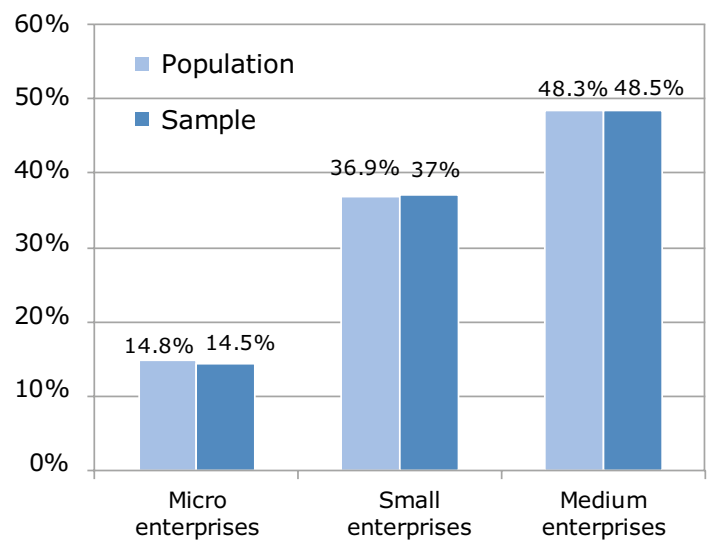

Figure 6. Sample composition and representativeness (1) - share of respondents by size (source: CSIL and authors' elaboration based on the survey carried out by CSIL in collaboration with CASE and BGK

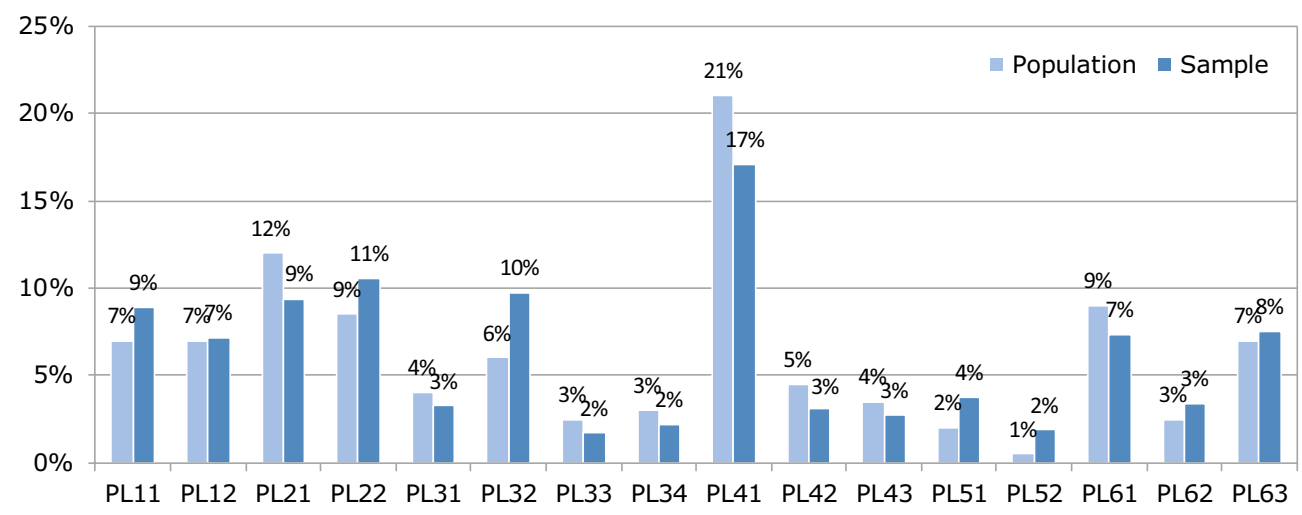

Figure 7. Sample composition and representativeness (2) - share of respondents by region (NUTS2) (source: CSIL and authors' elaboration based on the survey carried out by CSIL in collaboration with CASE and BGK)

Note: Łódzkie (PL11); Mazowieckie (PL12); Małopolskie (PL21); Śląskie (PL22); Lubelskie (PL31); Podkarpackie (PL32); Świętokrzyskie (PL33); Podlaskie (PL34); Wielkopolskie (PL41); Zachodniopomorskie (PL42); Lubuskie(PL43); Dolnośląskie (PL51); Opolskie (PL52); Kujawsko-pomorskie (PL61); Warmińsko-mazurskie (PL62); Pomorskie (PL63). 


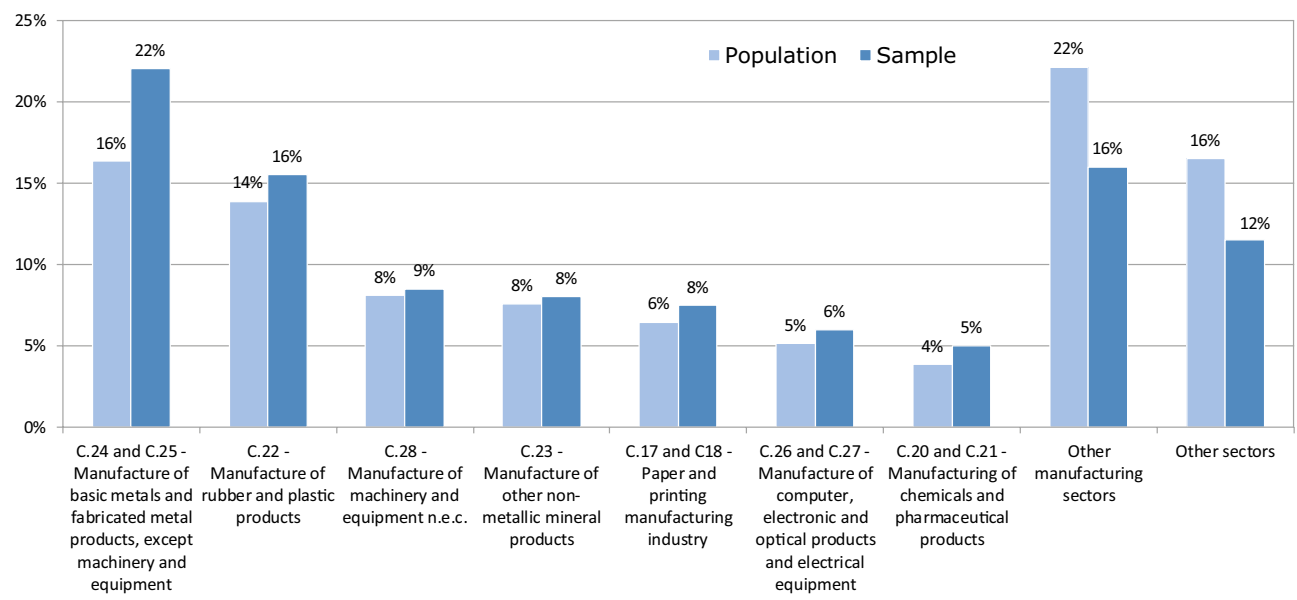

Figure 8. Sample composition and representativeness (3) - share of respondents by activity sector (NACE) (source: CSIL and authors' elaboration based on the survey carried out by CSIL in collaboration with CASE and BGK)

Table 2. Sample composition and representativeness (4) - value of public support and of investment project (source: CSIL and authors' elaboration based on the survey carried out by CSIL in collaboration with CASE and BGK)

\begin{tabular}{|l|c|c|c|c|}
\hline & \multicolumn{2}{|c|}{$\begin{array}{c}\text { Value of the public support } \\
\text { (thousands EUR on average per SME) }\end{array}$} & \multicolumn{2}{c|}{$\begin{array}{c}\text { Value of the investment project } \\
\text { (thousands EUR on average per SME) }\end{array}$} \\
\hline & sample & population & sample & population \\
\hline median & 692 & 641 & 1252 & 1172 \\
\hline average & 626 & 601 & 1216 & 1181 \\
\hline min & 19 & 19 & 32 & 32 \\
\hline max & 1001 & 971 & 3777 & 4555 \\
\hline st.dev. & 308 & 307 & 726 & 727 \\
\hline
\end{tabular}

\section{Ex-post assessment of policy effectiveness - the empirical test ${ }^{30}$}

\subsection{Descriptive statistics of the impact of $\mathrm{TC}^{31}$}

Most of the respondent firms were founded after 1990; the entrepreneurs are relatively young ( $52 \%$ are 30 to 45 years old; $64 \%, 26$ to 50 ) and well educated ( $72 \%$ have a master's degree). Half of the enterprises benefited from other forms of public support before 2009, so they already had some experience with the system of public support for businesses. The SMEs used the Technological Credit primarily to finance new production technologies (machinery, equipment) or intangible assets (patents and licenses). Around half of the firms flanked their investment in machinery with other types of expenditure, such as the construction, expansion or opening of production areas and external consulting services. The great majority of the firms - $84 \%$ - used the TC for a single investment project.

\footnotetext{
30 This section draws upon EC (2015c, pp. 30-55).

${ }^{31}$ Full descriptive statistics emerging from the survey can be found in EC (2015c), Volume II, Annex 1.
} 
The essential questions related to the results of the investment. As Figure 9 shows, the effects varied. In particular, the main effect - confirmed by $88 \%$ of the respondents - consisted in the broadening of the range of products or services; and $81 \%$ of the firms cited the introduction of a new production process or the upgrading of an existing one. Figure 10 plots the responses of firms with respect to six different economic outcomes. All of these effects turn out to be totally in keeping with the theory behind the intervention (CMO configuration 1 - Figure 3).

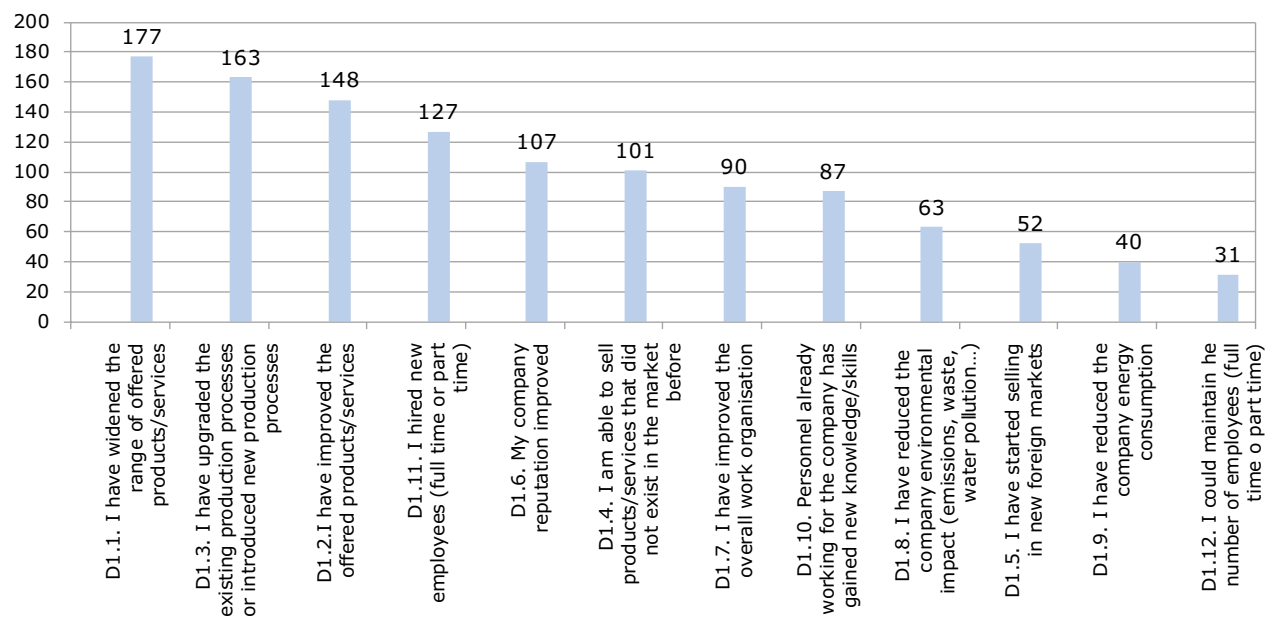

Figure 9. Investment results of the analyzed policy instrument (source: CSIL and authors' elaboration based on the survey carried out by CSIL in collaboration with CASE and BGK)

Note: Answer to the question: Did the implementation of the technological investment projects supported by BGK bring about any of the following changes to your enterprise? $n=200$ respondents. Enterprises could select more than one answer.

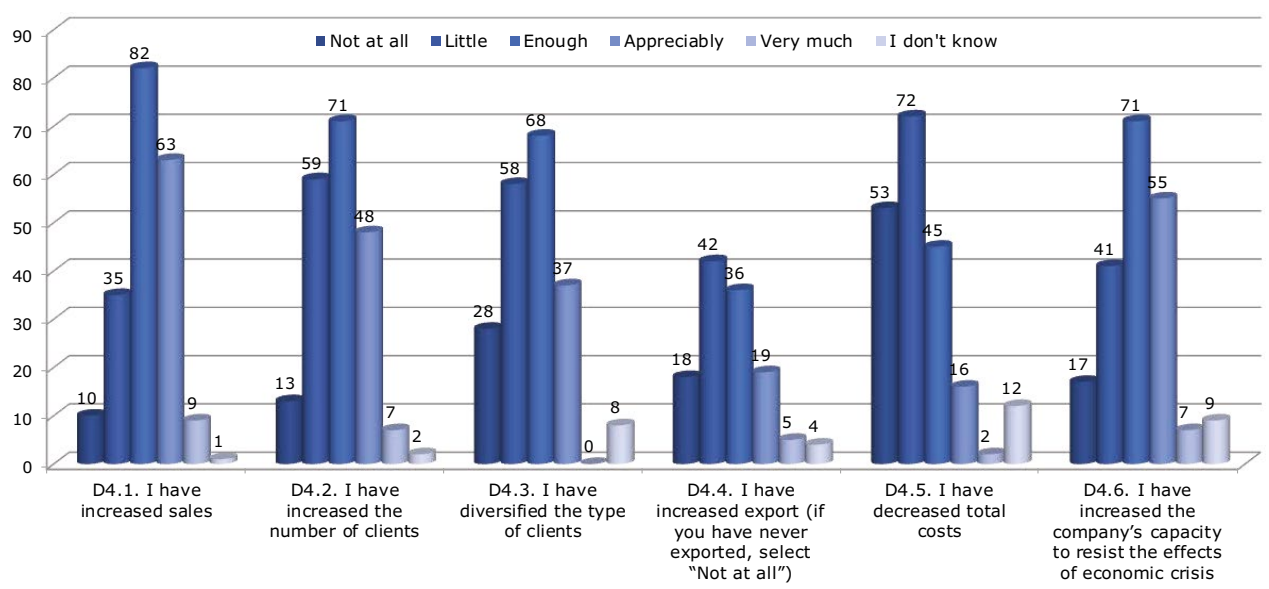

Figure 10. Economic results of the analyzed policy instrument (source: CSIL and authors' elaboration based on the survey carried out by CSIL in collaboration with CASE and BGK)

Note: Answer to the question: Which economic results has your enterprise already achieved thanks to the technological investments supported by BGK? $\mathrm{n}=200$ respondents (except question D4.4 where $\mathrm{n}=124$,- exporting enterprises only). 


\subsection{The BNA results}

To identify the variables with the strongest links to the expected results observed by the firms (sales or export gains, cost reductions), in the first instance we used the questionnaire answers to run standard regression analyses (logit and ordered logit models - the results are reported in EC, 2015c, Volume II, pp. 39-43).

However, the main objective of the research project was to discover the hidden patterns behind the responses of the firms without positing any specific structure of the relations between the variables. The search for any possible links among the variables was accordingly performed via the BNA method presented in Section $2.2^{32}$. The resulting directed acyclic graph (DAG) is shown in Figure 11. To facilitate interpretation, we grouped the variables into clusters of the most important indicators: direct changes produced by the investment projects (variables D.1), effects on economic performance (D.4), and behavioural changes (F.2).

DAG represents the network of related effects triggered by the investment project sustained by TC. It is worth noting that the BNA figure shows a joint probability distribution over a set of variables (which is not the same as pairwise correlation coefficients that we report separately) ${ }^{33}$.

The principal results for changes in economic performance as revealed by the $\mathrm{DAG}^{34}$ involve, first of all, the main changes generated directly by TC, denoted by the thick arrows, and consist in extension of the firms' range of products (D1.1), upgrading of production processes (D1.3), and market introduction of new, innovative products (D1.4).

Asked about the economic results achieved thanks to the technological investment supported by BGK (question D4), 154 respondents (77\%) reported that they had increased sales perceptibly ("enough", "appreciably" or "very much"). Half of the respondents reported a positive impact on exports as well, while for the other half this effect was limited or nil. The least significant effect reported was cost reduction: $27 \%$ said they had achieved no cost savings whatever, and $36 \%$ only limited savings. The DAG shows that these various economic outcomes are interlinked. In particular, an increase in sales (D4.1) is linked with an increase in the number of customers (D4.2) and customer types (D4.3), and with greater resilience in the face of recession (D4.6). Interestingly, sales gains are not linked to any specific modification within the enterprises' production function. Rather, this effect operated through export increases (see the link between D4.4 and D4.1). Other causes might be at work, but they are not brought out by the BNA, as their role is relatively weaker. This is the first important finding, which we comment below.

This international channel is important insofar as it suggests that a mechanism generating the observed outcomes may be typical of internationally oriented enterprises. Successful entry into new foreign markets (D1.5) is associated with an increase in exports (D4.4), but at the same time, the decision to move into new markets and the effects of international activity

\footnotetext{
32 To build the Bayesian Network we used Graphical Network Interface (GeNIe), a development environment for building graphical decision-theoretical models developed at the Decision Systems Laboratory, University of Pittsburgh. The documentation can be found at: https://dslpitt.org/genie/wiki/GeNIe_Documentation.

${ }^{33}$ Pairwise correlations between types of change variables (questions D.1), economic results (D.4) and behavioural changes (F.2) are reported in Appendix 4.

34 The robustness of the main results stemming from the network was checked by modifying some of the variables, for instance by the principal components method.
} 


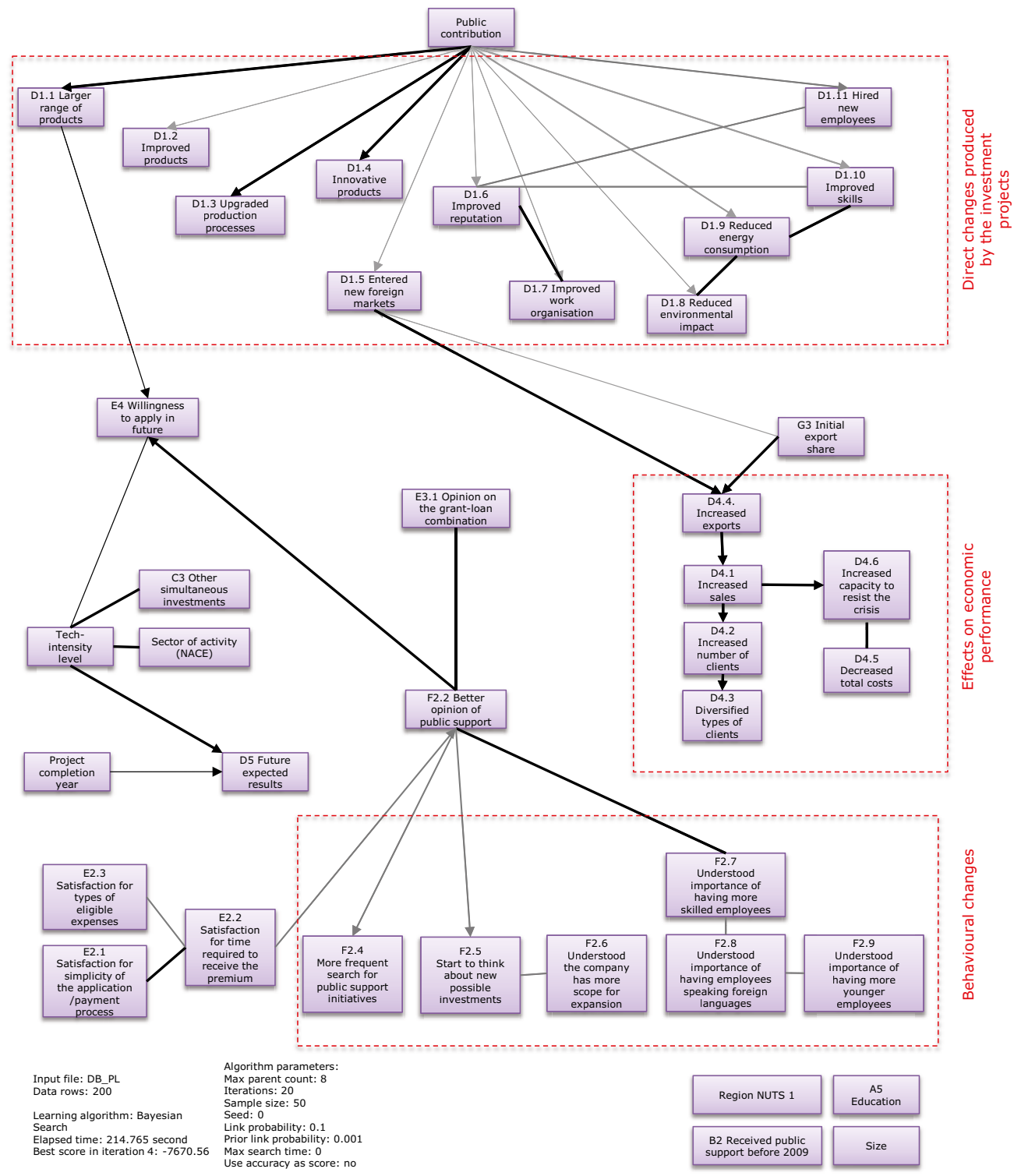

Figure 11. The change generated in Polish SMEs by the EU policy instrument (Technological Credit) according to the Bayesian Network Analysis (source: CSIL and authors' elaboration)

Note: Directed arrows show a causal relation; simple links between variables indicate correlation, without any certain causal direction. The thickness of the arrow reflects the magnitude of the correlation between the variables (estimated by GeNIe). Bottom right variables have been used as control variables but they do not result to be strongly linked to any other particular variable. Particular variables refer to the survey questions (see the questionnaire in Appendix 1). 
are strongly determined by the firm's initial export share (G3). Hence, the network shows that TC affected the export patterns of companies that were already present in foreign markets. This is an important result, indicating that there are some necessary preconditions for the success of the policy support. This concords with new-new trade theory (Melitz, 2003), which argues that preselection is crucial in successful export activity. It was not an aspect explicitly considered in the theory supporting the TC policy instrument.

Expectations of future economic results (D5) do not depend on the effects already observed, but rather on the year of the project (the more recent it is, the greater the expectations that economic results will materialise or increase in the future) and the firm's technology intensity (those in low-tech sectors are less optimistic). Given the considered years, in some export markets affected by the recession, this result is not surprising.

Importantly, the $\mathrm{BN}$ also reveals other relationships between changes generated by the policy instrument, such as the link between reduced energy consumption and improved workforce skills (D1.10) or those between reputational gains (D1.6), improved skills, new hiring (D1.11) and better work organization (D1.7). This suggests that the policy indirectly stimulated a whole series of factors benefitting business activities, which the standard assessment methodology could not have discovered (some limited dependent variable estimations were, however, tested at the preliminary research stage, see EC, 2015c, Volume II: 39-43).

The DAG reveals some important features of the behavioural changes resulting from EU financial support. According to BNA, behavioural change (questions F) is not related either to economic results already achieved (question D4) or to any specific changes within the firms (questions D1). On the other hand, the possible behavioural modifications considered in the questionnaire (F2.2-F2.9) are quite strongly interlinked. This suggests that a behavioural change impacts on the SME's functioning in multiple ways. The SMEs that have grasped the importance of a more highly skilled workforce (F2.7) also particularly appreciate the knowledge of foreign languages (F2.8). Having younger employees (F2.9) is also judged to be more valuable, as younger workers typically know foreign languages better. Another significant linkage is that between realising that the scope for expansion is greater than previously thought (F2.6) and considering new investments (F2.5).

Involvement in the TC scheme also changed firms' perspective on public support programmes. The results of BNA in Figure 11 show that the overwhelming majority of the recipient enterprises (over 80\%) say that they now have a better opinion of public support schemes for SMEs (F2.2). This is a significant "node" in the network - it relates to other behavioural changes (F2.4-F2.9) and to willingness (declared by of $86 \%$ of the respondents) to apply for other forms of technological investment support (E4).

The beneficiary SMEs are generally satisfied with the TC support received and the delivery procedures. As reported in an accompanying paper (EC, 2015c, Volume II, p. 30) almost $80 \%$ state that TC was effective in enhancing technology investment. These enterprises are accordingly likely to be interested in similar financial instruments in the future. However, only $28 \%$ of the respondents affirmed that without TC support they would have faced serious financial difficulties. This is a sign of preselection: the lack of credit per se was probably not a significant barrier for the enterprises that received TC. This finding is in accordance with the way the instrument was designed: the eligible firms should have already been able to show access to a commercial credit. 


\subsection{Test of the theory behind the intervention}

Using the BNA results, we can now return to the theory guiding the policy intervention and perform an ex-post reassessment of the validity of the CMO configurations. The results of this exercise are shown in Figure 12 (they correspond to the ex-ante CMO configurations depicted in Figures 3 and 4). The graph shows schematically which of the anticipated rela-

\section{CMO \#1: Economic effects of the Technological Credit: test of the theory}

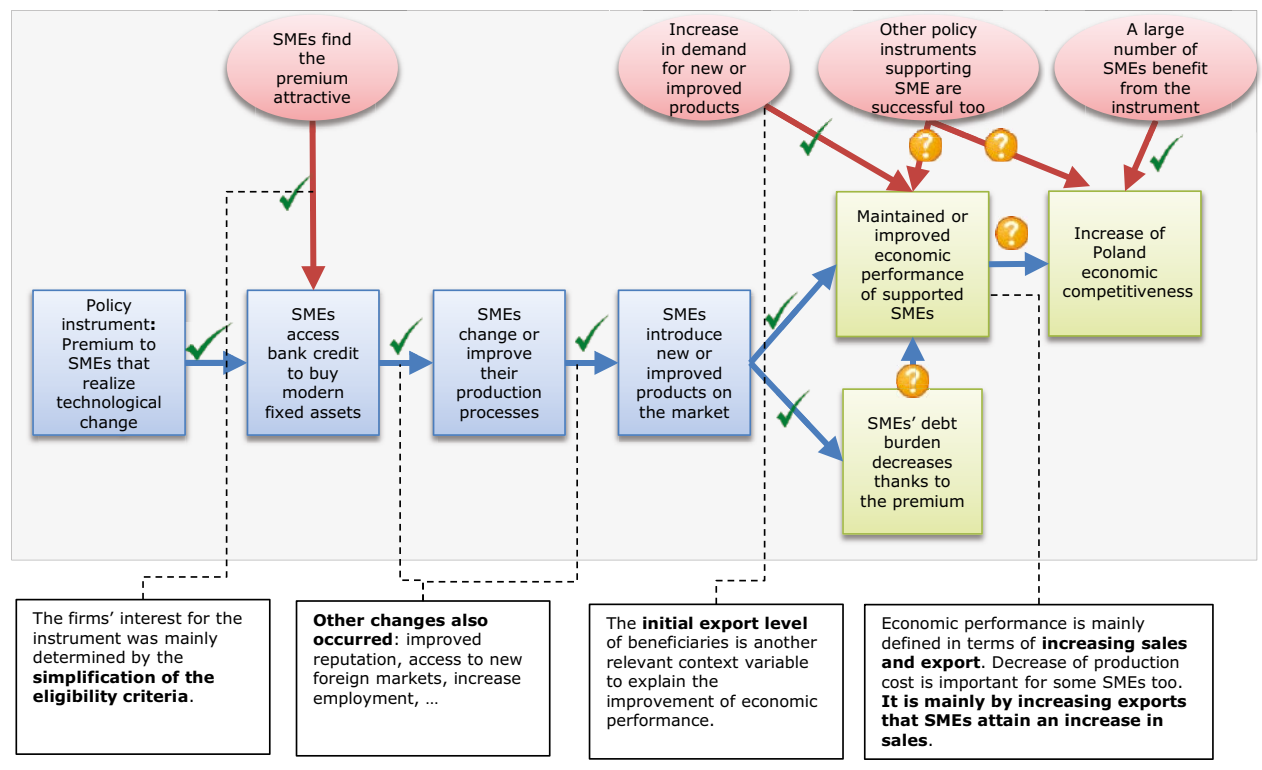

CMO \# 2: Good perception of the financial instruments: test of the theory

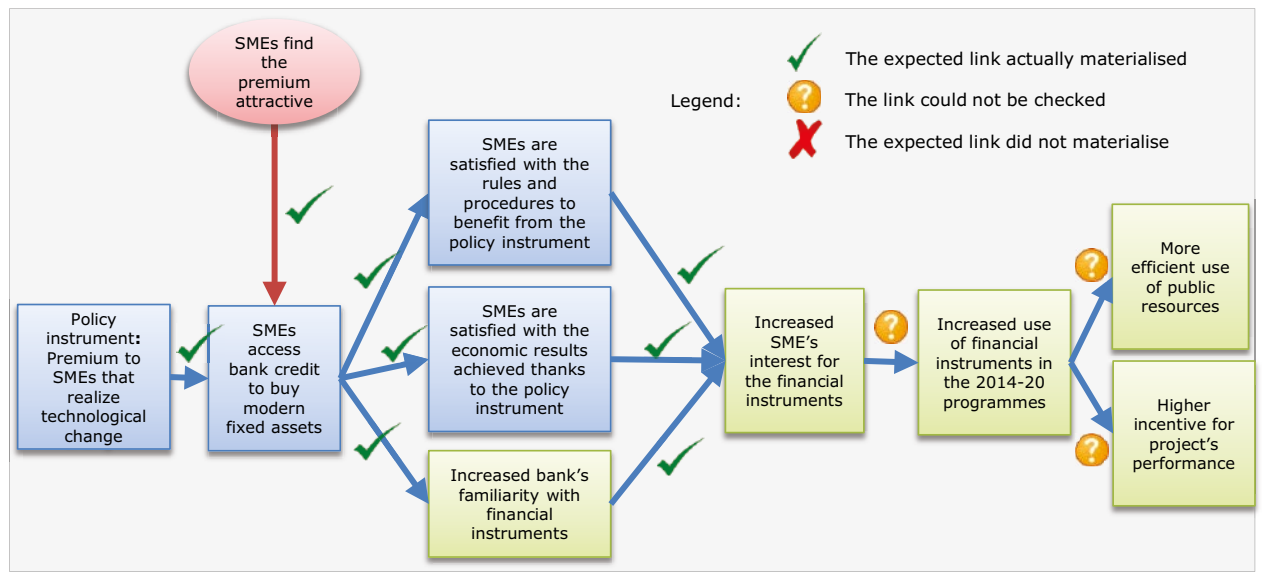

Figure 12. Test of the theory of intervention of the Technological Credit

(source: CSIL and authors' elaboration)

Note: Green-coloured boxes indicate the outcomes pursued by the policy maker; red-coloured circles indicate external conditions (i.e. specifications of context) upon which desired changes occur; bluecoloured boxes indicate the mechanisms at work along the causal chain leading to the outcomes. 
tions between mechanism, context and outcome variables actually materialised, according to the survey results.

Consistently with the theory, the policy enhanced technological progress among Polish SMEs, raising the technological level of their products and making them more competitive. The instrument was of special benefit to enterprises and SMEs already present in foreign markets. Interestingly, this effect was not anticipated, but we were able to detect it thanks to Bayesian Network Analysis.

The survey and BNA reveal that the beneficiary SMEs also experienced other kinds of change - linked to their behaviour - that were not specified in the theory behind the intervention and are not necessarily linked to the economically quantifiable results but may have great long-term significance. As our survey results show (see EC, 2015c, Volume 2, p. 31), after receiving the public TC support, almost $80 \%$ of the entrepreneurs report that they have started searching for information about other public programmes for SMEs, that they are thinking of new investments they had never considered before, that they realise their firm has greater scope for expansion, and that they are aware of the need more a more highly skilled workforce. Thanks to the positive results attained with TC, opinions of public support initiatives for SMEs improved in $85 \%$ of the firms surveyed.

\section{Conclusions and policy implications}

The aim of policy-makers is to foster growth by accelerating firms' technological innovation. To do so, they design policies with a more or less explicit theory in mind: essentially, a simplified representation of causal mechanisms given a context and a set of desired outcomes (objectives). Economists may influence policy-making by improving the theory and testing the effects of the instruments based on them.

This paper contributes to the literature on the effectiveness of public policies for technological progress in SMEs by empirical analysis of one specific policy instrument, namely Technological Credit, in the Polish experience. Standard ex-post policy assessment ordinarily involves counterfactual analysis with comparison of treated and control samples of firms. This common approach, however, does not bring out the mechanisms that underlie the changes triggered within the participating SMEs by the policy. The various forms of change considered here embraced both economically quantifiable effects and behavioural modifications. In essence, the question was what is hidden behind the observed change in firms' technological innovativeness.

We applied Bayesian Network Analysis in the framework of a theory-based ex-post evaluation. The advantage of this approach is the possibility of discovering the interrelated set of mechanisms of change and the complex causal links to the outcomes generated by the instrument. Additionally, we directly tested the consistency of the observed effects of EU Technological Credit with the hypotheses behind the logic of the policy. This differs from the simple observation of a statistical effect "after" a policy has been adopted, in that it relies on evidence of both economic and behavioural changes in the participating firms. In this sense our study carries important methodological implications: the BNA represents an advanced 
statistical tool for the evaluation of policy interventions but at the same time one that is highly intuitive and attractive to policy makers ${ }^{35}$.

In our case study, a third of all the firms taking part in the programme responded to our survey - a very high response rate for this type of inquiry; the sample is highly representative, as the characteristics of the respondents show an extremely close overlap with those of the total population of beneficiary firms. Given the general lack of studies on the effectiveness of EU innovation policy for firms in the new EU member states, our micro-level evidence on Polish firms is particularly valuable. But there is no reason to think the findings are specific to Polish firms - the mechanisms of change discovered may help illuminate the reasons for the success or failure of innovation policy support for SMEs more generally. Replication studies elsewhere would serve to confirm or rebut this intuition.

There is clear evidence that Technological Credit shifted firms' investment pattern. It accelerated the acquisition of machinery, equipment, and other fixed assets and was instrumental in broadening the beneficiary firms' product range, improving their production processes, and increasing their sales to greater numbers and a greater variety of customers. That is, the policy succeeded in producing the expected economic outcomes; and this even in a period of recession in some markets. Our main finding is, however, that the core driver of the process is the link between the adoption of new technology and greater penetration of foreign markets. This was unexpected, as the theory behind the Technological Credit instrument did not involve any hypothesis concerning the export orientation of the investment.

In fact, technological credit turns out to have been particularly advantageous for firms that were already exporters, much less so for domestically oriented firms. That is, what explains the overall positive outcome is the interplay between reduction in the cost of capital (implicit in the grant instrument) and access to wider markets. While the Polish SMEs are probably credit-rationed, attenuating this constraint, per se, was not the main and only causal mechanism leading to technological change.

What is more, the positive economic changes associated with the adoption of new technologies were linked to increased energy efficiency, improved employee skills and better overall work organisation, in a more complex pattern than the simple acquisition of new fixed assets. Hence, behavioural change in the participating firms is an important node in the network of effects that our study has mapped.

The logic of the policy intervention is only partially confirmed. To be sure, there was an increase in the technological intensity of the beneficiary firms, which was the main objective. However, perhaps unexpectedly, the main beneficiaries of TC were the financially sounder SMEs and those that were already present in foreign markets, before the support.

Our findings, though based on a case study for Poland, have broader policy implications as well. Technological Credit targeted to SMEs in the form that we studied here will not per se alter the behaviour of firms that are locked into existing market patterns, typically in the domestic market. Our results suggest that the impact of TC on firms may take the

\footnotetext{
35 For a more extensive discussion of the advantages of combining theory-based evaluation with BNA, see Giffoni, Salini and Sirtori (2018).
} 
form of a linkage between the adoption of new technology and the discovery of new, usually foreign, markets. As successful marketing abroad requires some previous experience, there will be path dependency. Hence, credit for innovative technologies would not appear to be the most effective instrument to foster investment by SMEs that simply need to expand their production capacity, but it can be deemed an effective policy instrument for those that have already begun a process of internationalisation. In other words, technological innovation and the discovery of new market opportunities are bound together, and a properly designed programme of Technological Credit can serve as catalyst.

Further research is needed to confirm the latter conjecture. First, as mentioned above, replication studies based on data for firms from other countries can serve to test whether our findings depend on some specific Polish circumstances. Ideally, such studies would need a context in which the policy instrument resembles the TC programme and there is some variability in the relative export orientation of the beneficiary firms. Second, admittedly our analysis of the context could be usefully extended. For example, we collected some qualitative evidence on other policy instruments in place, but one might well want to consider the possibility that firms are simultaneously seeking other forms of public support. Consequently, it would be interesting to study the impact of a set of different competitiveness-enhancing instruments on SMEs. This could detect combined or differentiated mechanisms behind the relative effectiveness of the policy instruments. One more direction for further research, finally, relates to the passage from the micro to the macro perspective. It is important, that is, to verify whether the long-run policy effects on firms can sustain aggregate changes in investment, productivity and export. This is far from self-evident and would require much larger sample and a longer time span.

\section{Acknowledgments}

This paper is based on the results of the "Ex post evaluation of Cohesion Policy programmes 2007-2013, focusing on the European Regional Development Fund (ERDF) and the Cohesion Fund (CF). Support to SMEs - Increasing research and innovation in SMEs and SME development" (Contract: 2014CE16BAT002). The evaluation was funded by the European Commission, Directorate-General for Regional and Urban Policy. The evaluation reports reflect the views only of the authors, and the Commission cannot be held responsible for any use which is made of the information contained therein. The authors are grateful to Elena Jarocinska (CASE - Center for Social and Economic Research) and Jan Teresiński (CASE - Center for Social and Economic Research) for field research and Francesco Giffoni (CSIL - Centre for Industrial Studies) for his contribution to the statistical analysis. Aleksandra Parteka acknowledges the support of the National Science Centre, Poland (Narodowe Centrum Nauki - NCN): the research has been conducted within a project financed by decision number DEC-2015/19/B/HS4/02884. The authors thank three anonymous referees and Tomasz Brodzicki for useful comment on an earlier version of this paper. 


\section{References}

Acs, Z. J., \& Audretsch, D. B. (1990). Innovation and small firms. Cambridge: MIT Press.

Acs, Z. J., Audretsch, D. B., Braunerhjelm, P., \& Carlsson, B. (2009). The knowledge spillover theory of entrepreneurship. Small Business Economics, 32(1), 15-30. https://doi.org/10.1007/s11187-008-9157-3

Aerts, K., \& Schmidt, T. (2008). Two for the price of one?: Additionality effects of R\&D subsidies: a comparison between Flanders and Germany. Research Policy, 37(5), 806-822. https://doi.org/10.1016/j.respol.2008.01.011

Alecke, B., Mitze, T., Reinkowski, J., \& Untiedt, G. (2012). Does firm size make a difference? Analysing the effectiveness of R\&D subsidies in East Germany. German Economic Review, 13(2), 174-195. https://doi.org/10.1111/j.1468-0475.2011.00546.x

Arrow, K. (1962). Economic welfare and the allocation of resources for inventions. In R. Nelson (Ed.), The rate and direction of inventive activity. Princeton: Princeton University Press. https://doi.org/10.1515/9781400879762-024

Astbury, B., \& Leeuw, F. L. (2010). Unpacking black boxes: mechanisms and theory building in evaluation. American Journal of Evaluation, 31(3), 363-381. https://doi.org/10.1177/1098214010371972

Astbury, B. (2013). Some reflections on Pawson's science of evaluation: a realist manifesto. Evaluation, 19(4), 383-401. https://doi.org/10.1177/1356389013505039

Bach, L., Matt, M., \& Wolff, S. (2014). How do firms perceive policy rationales behind the variety of instruments supporting collaborative R\&D? Lessons from the European Framework Programs. Technovation, 34(5), 327-337. https://doi.org/10.1016/j.technovation.2014.02.008

Baruk, J. (1997). Innovativeness of Polish enterprises in the initial period of system transformation. Technovation, 17(9), 477-530.

https://doi.org/10.1016/S0166-4972(97)00034-5

Battisti, G., \& Stoneman, P. (2010). How innovative are UK firms? Evidence from the fourth UK community innovation survey on synergies between technological and organisational innovations. British Journal of Management, 21(1), 187-206. https://doi.org/10.1111/j.1467-8551.2009.00629.x

Beck, T., \& Demirguc-Kunt, A. (2006). Small and medium-size enterprises: access to finance as a growth constraint. Journal of Banking and Finance, 30(11), 2931-2943. https://doi.org/10.1016/j.jbankfin.2006.05.009

Becker, B. (2015). Public R\&D policies and private R\&D investment: a survey of the empirical evidence. Journal of Economic Surveys, 29(5), 917-942. https://doi.org/10.1111/joes.12074

Béres, A., \& Závecz, G. (2016). Comparative counterfactual impact evaluation of repayable and nonrepayable financial assistances to SMEs in Hungary. Equinox Consulting.

Bérubé, C., \& Mohnen, P. (2009). Are firms that receive R\&D subsidies more innovative? Canadian Journal of Economics/Revue Canadienne d"économique, 42(1), 206-225.

Bronzini, R., \& Iachini, E. (2014). Are Incentives for R\&D Effective? Evidence from a regression discontinuity approach. American Economic Journal: Economic Policy, 6(4), 100-134.

https://doi.org/10.1257/pol.6.4.100

Bronzini, R., \& Piselli, P. (2016). The impact of R\&D subsidies on firm innovation. Research Policy, 45(2), 442-457. https://doi.org/10.1016/j.respol.2015.10.008

Brown, R., \& Mason, C. (2014). Inside the high-tech black box: a critique of technology entrepreneurship policy. Technovation, 34(12), 773-784. https://doi.org/10.1016/j.technovation.2014.07.013

Burgelman, R. A., Maidique, M. A., \& Wheelwright, S. C. (1996). Strategic management of technology and innovation (Vol. 2). Chicago, IL: Irwin. 
Camisón, C., \& Villar-López, A. (2014). Organisational innovation as an enabler of technological innovation capabilities and firm performance. Journal of Business Research, 67(1), 2891-2902. https://doi.org/10.1016/j.jbusres.2012.06.004

Carpenter, R. E., \& Petersen, B. C. (2002). Is the growth of small firms constrained by internal finance? Review of Economics and Statistics, 84(2), 298-309. https://doi.org/10.1162/003465302317411541

Carvalho, S., \& White, H. (2004). Theory-based evaluation: the case of social funds. American Journal of Evaluation, 25(2), 141-160. https://doi.org/10.1177/109821400402500202

Chen, Y. H., \& Nie, P. Y. (2014). Duopoly innovation under product externalities. Economic ResearchEkonomska Istraživanja, 27(1), 232-243. https://doi.org/10.1080/1331677X.2014.952092

Clausen, T. H. (2009). Do subsidies have positive impacts on R\&D and innovation activities at the firm level? Structural Change and Economic Dynamics, 20(4), 239-253. https://doi.org/10.1016/j.strueco.2009.09.004

Cox, D., \& Rigby, J. (2013). Innovation policy challenges for the 21st century. Routledge, Abingdon, Oxon.

Czarnitzki, D., \& Hottenrott, H. (2011). R\&D investment and financing constraints of small and medium-sized firms. Small Business Economics, 36(1), 65-83. https://doi.org/10.1007/s11187-009-9189-3

Czarnitzki, D., \& Licht, G. (2006). Additionality of public R\&D grants in a transition economy. Economics of Transition, 14(1), 101-131. https://doi.org/10.1111/j.1468-0351.2006.00236.x

Czarnitzki, D., \& Lopes-Bento, C. (2013). Value for money? New microeconometric evidence on public R\&D grants in Flanders. Research Policy, 42(1), 76-89. https://doi.org/10.1016/j.respol.2012.04.008

Czarnitzki, D., Hanel, P., \& Rosa, J. M. (2011). Evaluating the impact of R\&D tax credits on innovation: a microeconometric study on Canadian firms. Research Policy, 40(2), 217-229.

https://doi.org/10.1016/j.respol.2010.09.017

Czemiel-Grzybowska, W., \& Skowronek-Mielczarek, A. (2017). Entrepreneurship research in the Poland. Technological and Economic Development of Economy, 23(3), 504-519. https://doi.org/10.3846/20294913.2015.1070770

Daly, R., Shen, Q., \& Aitken, S. (2011). Learning Bayesian networks: approaches and issues. The Knowledge Engineering Review, 26(2), 99-157. https://doi.org/10.1017/S0269888910000251

Dawid, A. P. (2000). Causal inference without counterfactuals. Journal of the American Statistical Association, 95(450), 407-424. https://doi.org/10.1080/01621459.2000.10474210

Dodgson, M., Gann, D. M., \& Salter, A. (2008). The management of technological innovation: strategy and practice. Oxford: Oxford University Press.

Dolfsma, W., \& Seo, D. (2013). Government policy and technological innovation - a suggested typology. Technovation, 33(6), 173-179. https://doi.org/10.1016/j.technovation.2013.03.011

Dosi, G., Freeman, C., Nelson, R., Silverberg, G., \& Soete, L. G. (Eds.). (1988). Technical change and economic theory. London: Pinter.

Duda, J. (2012). Role and importance of technological credits in financing of innovative investments by small and medium-sized enterprises in Poland and Lesser Poland. AGH Managerial Economics, 12, 25-40. https://doi.org/10.7494/manage.2012.12.25

EBRD. (2015a). EBRD Transition Report 2015-2016. Retrieved from http://www.ebrd.com/news/publications/transition-report/ebrd-transition-report-201516.html

EBRD. (2015b). Business Environment and Enterprise Performance Survey (BEEPS) V. Retrieved from http://ebrd-beeps.com/wp-content/uploads/2015/09/BEEPSV-complete.pdf

EC. (2010). Europe 2020: a strategy for smart, sustainable and inclusive growth, communication from the commission. European Commission, Brussels.

EC. (2015a). Support to SMEs - increasing research and innovation in SMEs and SME development, work package 2, first intermediate report. Ex post evaluation of Cohesion Policy programmes 2007-2013, 
focusing on the European Regional Fund (ERDF) and the Cohesion Fund (CF). Contract number 2014CE16BAT002. Authored by CSIL, in partnership with CSES and ZEW. Retrieved from http:// ec.europa.eu/regional_policy/sources/docgener/evaluation/pdf/expost2013/wp2_1st_intermediate_report_1.pdf

EC. (2015b). Support to SMEs - increasing research and innovation in SMEs and SME development, work package 2, Poland. operational programme 2007-2013 innovative economy, case study. Ex post evaluation of Cohesion Policy programmes 2007-2013, focusing on the European Regional Fund (ERDF) and the Cohesion Fund (CF). Contract number 2014CE16BAT002. Authored by Elena Jarocinska (CASE) and Jan Teresiński (CASE) in partnership with CSIL. Retrieved from http://ec.europa.eu/ regional_policy/sources/docgener/evaluation/pdf/expost2013/wp2_case_study_pl.pdf

EC. (2015c). Support to SMEs - increasing research and innovation in SMEs and SME development, third intermediate report, work package 2. Ex post evaluation of Cohesion Policy programmes 2007-2013, focusing on the European Regional Fund (ERDF) and the Cohesion Fund (CF). Contract number 2014CE16BAT002. Authored by CSIL, in partnership with CSES and ZEW. Vol. I. Retrieved from http://ec.europa.eu/regional_policy/sources/docgener/evaluation/pdf/expost2013/wp2_3rd_intermediate_report_1.pdf.pdf Vol. II. Retrieved from http://ec.europa.eu/regional_policy/sources/docgener/evaluation/pdf/expost2013/wp2_3rd_intermediate_report_2.pdf.pdf

EC. (2016). European innovation scoreboard 2016. Retrieved from http://ec.europa.eu/growth/industry/ innovation/facts-figures/scoreboards_en

Edler, J., Cunningham, P., \& Gök, A. (Eds.). (2016). Handbook of innovation policy impact. Cheltenham, UK: Edward Elgar Publishing. https://doi.org/10.4337/9781784711856

Edler, J., \& Fagerberg, J. (2017). Innovation policy: what, why, and how. Oxford Review of Economic Policy, 33(1), 2-23. https://doi.org/10.1093/oxrep/grx001

Faber, J., van Dijk, J., \& van Rijnsoever, F. (2016). Incentives and barriers for R\&D-based SMEs to participate in European research programs: an empirical assessment for the Netherlands. Science and Public Policy, 43(3), 414-428. https://doi.org/10.1093/scipol/scv050

Foreman-Peck, J. (2013). Effectiveness and efficiency of SME innovation policy. Small Business Economics, 41(1), 55-70. https://doi.org/10.1007/s11187-012-9426-Z

Gelman, A., Carlin, J. B., Stern, H. S., \& Rubin, D. B. (2014). Bayesian data analysis (Vol. 2). Boca Raton, FL, USA: Chapman and Hall/CRC.

Giffoni, F., Salini, S., \& Sirtori, E. (2018). Evaluating business support measures: the Bayesian network approach. Evaluation, 24(2), 133-152. https://doi.org/10.1177/1356389018767179

Gök, A., \& Edler, J. (2012). The use of behavioural additionality evaluation in innovation policy making. Research Evaluation, 21(4), 306-318. https://doi.org/10.1093/reseval/rvs015

Golejewska, A., \& Gajda, D. (2015). How Polish firms use the EU funds for innovative projects? Final evaluation of Pomerania region in Poland. In Innovation, Finance, and the Economy (pp. 1-13). Springer International Publishing. https://doi.org/10.1007/978-3-319-15880-8_1

Hadjimanolis, A. (1999). Barriers to innovation for SMEs in a small less developed country (Cyprus). Technovation, 19(9), 561-570. https://doi.org/10.1016/S0166-4972(99)00034-6

Heckerman, D., Geiger, D., \& Chickering, D. M. (1995). Learning Bayesian networks: the combination of knowledge and statistical data. Machine Learning, 20, 197-243. https://doi.org/10.1007/BF00994016

Holmes, T. J., Levine, D. K., \& Schmitz, J., J. A. (2012). Monopoly and the incentive to innovate when adoption involves switchover disruptions. American Economic Journal: Microeconomics, 4(3), 1-33. https://doi.org/10.1257/mic.4.3.1

Hottenrott, H., \& Lopes-Bento, C. (2014). (International) R\&D collaboration and SMEs: The effectiveness of targeted public R\&D support schemes. Research Policy, 43(6), 1055-1066.

https://doi.org/10.1016/j.respol.2014.01.004 
Hueske, A. K., \& Guenther, E. (2015). What hampers innovation? External stakeholders, the organisation, groups and individuals: a systematic review of empirical barrier research. Management Review Quarterly, 65(2), 113-148. https://doi.org/10.1007/s11301-014-0109-5

Jasinski, A. H. (2003). Has innovation policy an influence on innovation? The case of a country in transition. Science and Public Policy, 30(6), 431-440. https://doi.org/10.3152/147154303781780245

Jasinski, A. H. (2014). Innovation policy instruments: do they work in Poland? International Journal of Transitions and Innovation Systems, 3(3), 269-290. https://doi.org/10.1504/IJTIS.2014.065699

Kelley, D., Singer, S., \& Herrington, M. (2016). Global entrepreneurship monitor - 2015/16 global report. Retrieved from http://www.gemconsortium.org/report/49480

Konings, J., Rizov, M., \& Vandenbussche, H. (2003). Investment and financial constraints in transition economies: micro evidence from Poland, the Czech Republic, Bulgaria and Romania. Economics Letters, 78(2), 253-258. https://doi.org/10.1016/S0165-1765(02)00210-0

Lauritzen, S. L., \&. Spiegelhalter, D. J (1988). Local computations with probabilities on graphical structures and their application to expert systems (with discussion). Journal of the Royal Statistical Society. Series B (Methodological), 50(2), 157-224.

Lee, K., Park, I., \& Yoon, B. (2016). An approach for R\&D partner selection in alliances between large companies, and small and medium enterprises (SMEs): application of Bayesian network and patent analysis. Sustainability, 8(2), 117. https://doi.org/10.3390/su8020117

Lewandowska, A., Stopa, M., \& Humenny, G. (2015). The European Union structural funds and regional development. The perspective of small and medium enterprises in Eastern Poland. European Planning Studies, 23(4), 785-797. https://doi.org/10.1080/09654313.2014.970132

Madrid-Guijarro, A., Garcia, D., \& Van Auken, H. (2009). Barriers to innovation among Spanish manufacturing SMEs. Journal of Small Business Management, 47(4), 465-488.

https://doi.org/10.1111/j.1540-627X.2009.00279.x

Martínez-Ros, E., \& Labeaga, J. M. (2009). Product and process innovation: persistence and complementarities. European Management Review, 6(1), 64-75. https://doi.org/10.1057/emr.2009.4

Massa, S., \& Testa, S. (2008). Innovation and SMEs: misaligned perspectives and goals among entrepreneurs, academics, and policy makers. Technovation, 28(7), 393-407.

https://doi.org/10.1016/j.technovation.2008.01.002

Mazzucato, M., \& Semieniuk, G. (2017). Public financing of innovation: new questions. Oxford Review of Economic Policy, 33(1), 24-48. https://doi.org/10.1093/oxrep/grw036

Melitz, M. J. (2003). The impact of trade on intra-industry reallocations and aggregate industry productivity. Econometrica, 71(6), 1695-1725. https://doi.org/10.1111/1468-0262.00467

Mole, K. F., Hart, M., Roper, S., \& Saal, D. S. (2009). Assessing the effectiveness of business support services in England. Evidence from a theory-based evaluation. International Small Business Journal, 27(5), 557-582. https://doi.org/10.1177/0266242609338755

Moral-Arce, I., \& Paniagua, M. (2016). An impact evaluation of the EU funds on research and development in Spanish companies in 2007-2011. Papeles de Trabajo 7/2016. Istituto de Estudios Fiscales. Retrieved from http://www.ief.es/documentos/recursos/publicaciones/papeles_trabajo/2016_07.pdf

Nadkarni, S., \& Shenoy, P. P. (2001). A Bayesian network approach to making inferences in causal maps. European Journal of Operational Research, 128(3), 479-498.

https://doi.org/10.1016/S0377-2217(99)00368-9

Neapolitan, R. E. (2004). Learning Bayesian networks. Upper Saddle River, NJ: Pearson Prentice Hall.

Nie, P. Y. (2013). Innovation under spatial duopoly. Prague Economic Papers, 23(4), 474-486. https://doi.org/10.18267/j.pep.463

Nieć, M. (2015). Innovation activity of enterprises in Poland in comparison to other European countries. In P. Zadura-Lichota (Ed.), Innovative entrepreneurship. Revealed and hidden potential for innovation in Poland. Warsaw: Polish Agency for Enterprise Development. 
Nielsen, T. D., \& Jensen, F. V. (2009). Bayesian networks and decision graphs. Springer Science and Business Media.

OECD. (2015). The innovation imperative: contributing to productivity, growth and well-being. Paris: OECD Publishing. https://doi.org/10.1787/9789264239814-en

Pawson, R., \& Tilley, N. (1997). Realistic evaluation. Thousand Oaks, CA, US: Sage Publications, Inc.

Piva, M., Santarelli, E., \& Vivarelli, M. (2005). The skill bias effect of technological and organisational change: evidence and policy implications. Research Policy, 34(2), 141-157. https://doi.org/10.1016/j.respol.2004.11.005

Porter, M. E., Sachs, J., \& McArthur, J. (2001). Executive summary: competitiveness and stages of economic development. The Global Competitiveness Report, 2002, 16-25.

Radicic, D., Pugh, G., Hollanders, H., Wintjes, R., \& Fairburn, J. (2016). The impact of innovation support programs on small and medium enterprises innovation in traditional manufacturing industries: an evaluation for seven European Union regions. Environment and Planning C: Government and Policy, 34(8), 1425-1452. https://doi.org/10.1177/0263774X15621759

Romer, P. M. (1990). Endogenous technological change. Journal of Political Economy, 98(5, Part 2), S71-S102. https://doi.org/10.1086/261725

Russell, S. J., \& Norvig, P. (2003). Artificial intelligence: a modern approach. Upper Saddle River, NJ: Pearson Prentice Hall.

Scherer, F. M. (1986). Innovation and growth: Schumpeterian perspectives. The MIT Press.

Spiegelhalter, D., Dawid, A., Lauritzen, S., \& Cowell, R. (1993). Bayesian analysis in expert systems. Statistical Science, 8, 219-282. https://doi.org/10.1214/ss/1177010888

Tang, J. M. (2006). Competition and innovation behavior. Research Policy, 35(1), 68-82. https://doi.org/10.1016/j.respol.2005.08.004

Teece, D. J. (1986). Profiting from technological innovation: implications for integration, collaboration, licensing and public policy. Research Policy, 15(6), 285-305. https://doi.org/10.1016/0048-7333(86)90027-2

Tilley, N. (2000). Realistic evaluation: an overview. In Founding Conference of the Danish Evaluation Society (Vol. 8). Retrieved from http://healthimpactassessment.pbworks.com/f/Realistic+evaluation+an+overview+-+UoNT+England+-+2000.pdf

Venturini, F., Aristei, D., \& Sterlacchini, A. (2016). Effectiveness of R\&D subsidies during the crisis: firm-level evidence across EU countries. Economics of Innovation and New Technology, 26(6), 1-20.

Węcławska, D., Tarnawa, A., Nieć, M., \& Zbierowski, P. (2015). Global entrepreneurship monitor Poland. Warsaw: Polish Agency for Enterprise Development.

Weiss, C. H. (1997a). How can theory-based evaluation make greater headway? Evaluation Review, 21(4), 501-524. https://doi.org/10.1177/0193841X9702100405

Weiss, C. H. (1997b). Theory-based evaluation: past, present, and future. New Directions for Evaluation, 1997(76), 41-55. https://doi.org/10.1002/ev.1086

Zúñiga-Vicente, J. Á., Alonso-Borrego, C., Forcadell, F. J., \& Galán, J. I. (2014). Assessing the effect of public subsidies on firm R\&D investment: a survey. Journal of Economic Surveys, 28(1), 36-67. https://doi.org/10.1111/j.1467-6419.2012.00738.x 